\title{
Anion Transport Processes in the Mammalian Superficial Proximal Straight Tubule
}

\author{
James A. Schafer and Thomas E. Andreoli \\ with the technical assistance of SUSAN L. Troutman \\ From the Division of Nephrology, Department of Medicine, and the Department of \\ Physiology and Biophysics, University of Alabama, Birmingham, Alabama 35294
}

\begin{abstract}
A B S T R A C T The experiments reported in this paper were designed to evaluate some of the characteristics of anion transport processes during fluid absorption from superficial proximal straight tubules isolated from rabbit kidney. We measured net chemical $\mathrm{Cl}^{-}$flux during fluid absorption from tubules perfused and bathed with Krebs-Ringer buffers containing $113.6 \mathrm{mM} \mathrm{Cl}^{-}$, $10 \mathrm{mM}$ acetate, and $25 \mathrm{mM} \mathrm{HCO}_{3}{ }^{-}$at $\mathrm{pH} 7.4$; assessed the effects of carbonic anhydrase inhibitors on net fluid absorption in the presence and absence of $\mathrm{CO}_{2}$; and evaluated the influx and efflux coefficients for $\left[{ }^{14} \mathrm{C}\right]$ acetate transport at $37^{\circ} \mathrm{C}$, at $21^{\circ} \mathrm{C}$, and in the presence of carbonic anhydrase inhibitors. The experimental data show that, for this nephron segment, net $\mathrm{Cl}^{-}$flux accompanies approximately $27.5 \%$ of net $\mathrm{Na}^{+}$absorption; and net $\mathrm{Cl}^{-}$absorption may be accounted for by a passive transport process, primarily diffusional in nature. Fluid absorption in this nephron segment is reduced $40-60 \%$ by carbonic anhydrase inhibitors, but only when the tubules are exposed to $95 \% \mathrm{O}_{2}-5 \% \mathrm{CO}_{2}$ rather than $100 \% \mathrm{O}_{2}$. Thus, it seems probable that approximately half of $\mathrm{Na}^{+}$absorption in these tubules may be rationalized in terms of a carbonic anhydrasedependent $\mathrm{CO}_{2}$ hydration process. In addition, there may occur in these isolated proximal tubules an acetazolamide-insensitive moiety of $\mathrm{HCO}_{3}^{-}$absorption comparable to that observed for proximal tubules in vivo. Finally, we provide evidence that net efflux of luminal acetate is due to metabolic energy-dependent processes
\end{abstract}

Preliminary reports of some of the observations in this paper appeared in abstract form in 1975. Clin. Res. 23: 544A, and Am. Soc. Nephrol. Abs. 8: 94.

J. A. Schafer is an Established Investigator (71-177) of the American Heart Association, and T. E. Andreoli is the recipient of a Career Development Award (5-KO4-GM18161) from the National Institutes of Health.

Received for publication 27 October 1975 and in revised form 8 March 1976. other than $\mathrm{CO}_{2}$ hydration and may, under appropriate conditions, account for approximately one-fourth of net $\mathrm{Na}^{+}$absorption.

\section{INTRODUCTION}

The characteristics of salt and volume absorption by the mammalian proximal straight tubule, a nephron segment ordinarily inaccessible to in vivo micropuncture, are not fully understood. When superficial proximal straight tubule segments isolated from rabbit kidney are perfused and bathed at $37^{\circ} \mathrm{C}$ with symmetrical KrebsRinger $(\mathrm{KR})^{1}$ solutions containing $113.6 \mathrm{mM} \mathrm{Cl}^{-}, 25$ $\mathrm{mM} \mathrm{HCO}{ }^{-}$, and $10 \mathrm{mM}$ acetate at $\mathrm{pH} 7.4\left(\mathrm{HCO}_{3}-\mathrm{KR}\right.$ buffer), isotonic fluid absorption may be accounted for quantitatively by net lumen-to-bath $\mathrm{Na}^{+}$flux $(1,2)$; the transepithelial voltage is -1.0 to $-1.5 \mathrm{mV}$, lumen negative $(1,3)$; and, in contrast to results obtained in isolated proximal convoluted tubules (4-6), neither net fluid absorption nor the transepithelial voltage depends appreciably on the presence of glucose and/or alanine in perfusing solutions (1).

As in the in vivo mammalian proximal tubule $(7,8)$, the $\mathrm{Cl}^{-}$content of tubular fluid in isolated superficial proximal straight tubules perfused with symmetrical $\mathrm{HCO}_{3}-\mathrm{KR}$ solutions rises appreciably during volume absorption (1). And in the setting of lumen-to-bath $\mathrm{Cl}^{-}$ concentration gradients, the transepithelial voltage in Cl-permselective superficial proximal straight tubules becomes lumen positive: when these tubules are perfused with $\mathrm{Cl}-\mathrm{KR} / \mathrm{CO}_{2}$ buffers ${ }^{2}$ containing $138.6 \mathrm{mM}$

\footnotetext{
${ }^{1}$ Abbreviations used in this paper: $J^{d}$, diffusional component of flux; $J^{e}$, entrained component of flux; $J_{v}$, net fluid transport; $K^{e}$, efflux ; $K^{i}$, influx; KR, Krebs-Ringer solution; $P$, ionic permeability coefficient ; $\sigma$, reflection coefficient.

${ }^{2}$ Two types of $\mathrm{KR}$ buffers containing high $\mathrm{Cl}^{-} / \mathrm{HCO}_{3}^{-}$ ratios are referred to in this paper. One of these, described above, contains $3.8 \mathrm{mM} \mathrm{HCO}^{-}, \mathrm{pH} 6.6$, and is bubbled with
} 
$\mathrm{Cl}^{-}, 3.8 \mathrm{mM} \mathrm{HCO}{ }^{-}$, and $10 \mathrm{mM}$ acetate ( $\mathrm{pH} \mathrm{6.6)}$, and bathed with $\mathrm{HCO}_{3}-\mathrm{KR}$ buffers, the transepithelial voltage is in the range +3.0 to $+3.8 \mathrm{mV}$, lumen positive $(1,9)$. Similar considerations may apply to transepithelial voltages in isolated superficial proximal convoluted tubules (4-6), and the recent micropuncture observations of Barratt et al. (10) have provided evidence for lumen-positive transepithelial voltages in late portions of the in vivo superficial proximal tubule.

In contrast, Kawamura et al. (11) have observed that in juxtamedullary proximal straight tubules transepithelial lumen-to-bath $\mathrm{NaCl}$ concentration gradients result in lumen negative transepithelial voltages. These workers have also noted that proximal straight tubules originating from juxtamedullary glomeruli are $\mathrm{Na}^{+}$, rather than $\mathrm{Cl}^{-}$permselective. Accordingly, we wish to emphasize that the experimental results and conclusions presented in this paper are restricted to transport events in proximal straight tubules originating from glomeruli in superficial regions of rabbit cortex.

Our earlier observations (9) showed that passive net $\mathrm{NaCl}$ flux from lumen to bath, driven by transepithelial $\mathrm{Cl}^{-}$concentration gradients, attendant lumen-positive transepithelial voltages, and, to a lesser extent, entrainment with volume flow, might account for approximately $40 \%$ of the fluid absorbed from superficial proximal straight tubules perfused and bathed with Cl-KR/ $\mathrm{CO}_{2}$ and $\mathrm{HCO}_{3}-\mathrm{KR}$ solutions, respectively. Nevertheless, it is clear that fluid absorption in this nephron segment depends, in the final analysis, on transport processes requiring metabolic energy, since $(a)$ when these tubules are perfused and bathed with symmetrical $\mathrm{HCO}_{3}-\mathrm{KR}$ solutions, both net fluid transport $\left(J_{v}\right)$ and transepithelial voltage $\left(V_{\bullet}\right)$ become zero either upon cooling from $37^{\circ}$ to $21^{\circ} \mathrm{C}$ or at $37^{\circ} \mathrm{C}$, by adding 0.1 $\mathrm{mM}$ ouabain to the bath $(1,2,9)$; and $(b)$ the rise in intraluminal $\mathrm{Cl}^{-}$concentration during fluid absorption (1) must depend on preferential absorption of anions other than $\mathrm{Cl}^{-}$with $\mathrm{Na}^{+}$. Clearly, additional information is required to describe salt flows in this nephron segment.

In the case of anion transport, certain issues merit particular consideration. In isolated superficial proximal straight tubules (1), we noted that net $\mathrm{Na}^{+}$absorption was approximately $15-20 \%$ of the unidirectional $\mathrm{Cl}^{-}$ flux, estimated by using ${ }^{86} \mathrm{Cl}^{-}$, either from lumen to bath or from bath to lumen. Since the magnitude of net $\mathrm{Na}^{+}$flux was within the range of experimental error for unidirectional tracer $\mathrm{Cl}^{-}$fluxes, it was not possible to evaluate quantitatively the $\mathrm{Cl}^{-}$component of

$95 \% \quad \mathrm{O}_{2}-5 \% \quad \mathrm{CO}_{2}$; for convenience, such a solution will be termed $\mathrm{Cl}-\mathrm{KR} / \mathrm{CO}_{2}$ buffer. The second type of $\mathrm{Cl}-\mathrm{KR}$ solution contains no $\mathrm{HCO}_{3}^{-}, \mathrm{pH} \mathrm{7.4,} \mathrm{and} \mathrm{is} \mathrm{bubbled} \mathrm{with} 100 \%$ $\mathrm{O}_{2}$; this solution will be termed $\mathrm{Cl}-\mathrm{KR} / \mathrm{O}_{2}$ buffer. the anion flux accompanying net $\mathrm{Na}^{+}$absorption. Second, $\mathrm{HCO}_{3}^{-}$and acetate are, after $\mathrm{Cl}^{-}$, the predominant anions in the $\mathrm{HCO}_{3}-\mathrm{KR}$ solutions we used to perfuse isolated superficial proximal straight tubules $(1,9)$. Accordingly, it is appropriate to inquire about the magnitude of $\mathrm{Cl}^{-}$flux accompanying $\mathrm{Na}^{+}$absorption, the contributions of $\mathrm{HCO}_{3}^{-}$and/or acetate as counterions for $\mathrm{Na}^{+}$absorption, and hence to the rise in tubular fluid $\mathrm{Cl}^{-}$concentration during volume absorption, and to consider the possible mechanisms involved in $\mathrm{HCO}_{3}^{-}$ and acetate absorption.

The experiments reported in this paper were designed to evaluate aspects of these issues in superficial proximal straight tubules isolated from rabbit kidney. We measured net $\mathrm{Cl}^{-}$flux during fluid absorption by chemical techniques, assessed the effects of carbonic anhydrase inhibitors on net fluid absorption in the presence and absence of $\mathrm{CO}_{2}$, and evaluated the influx and efflux coefficients for $\left[{ }^{14} \mathrm{C}\right]$ acetate transport under a variety of experimental conditions. The experimental data show that, for this nephron segment, net $\mathrm{Cl}^{-}$flux accompanies approximately $27.5 \%$ of net $\mathrm{Na}^{+}$absorption; and net $\mathrm{Cl}^{-}$absorption may be accounted for by a passive transport process, primarily diffusional in nature. Fluid absorption in this nephron segment is reduced $40-60 \%$ by carbonic anhydrase inhibitors, but only $\begin{array}{lllll}\text { when the tubules are exposed to } 95 \% & \mathrm{O}_{2}-5 \% & \mathrm{CO}_{2}\end{array}$ rather than $100 \% \mathrm{O}_{2}$. Thus it seems probable that at least half of $\mathrm{Na}^{+}$absorption in these tubules may be rationalized in terms of a carbonic anhydrase-dependent $\mathrm{CO}_{2}$ hydration process (12-20). In addition, in these isolated proximal tubules an acetazolamideinsensitive moiety of $\mathrm{HCO}_{3}^{-}$absorption may occur, comparable to that observed for proximal tubules in vivo (12-20). Finally, we provide evidence that net efflux of luminal acetate occurs as a consequence of metabolic energy-dependent processes other than $\mathrm{CO}_{2}$ hydration and may, under appropriate conditions, account for approximately one fourth of net $\mathrm{Na}^{+}$absorption.

\section{METHODS}

The techniques used for studying transport events in proximal straight tubules isolated from superficial regions of rabbit renal cortex are nearly the same as those developed originally by Burg et al. $(2,21)$. Details of the methodology, as utilized in this laboratory, have been presented previously $(1,9)$; unless otherwise indicated, these techniques were utilized without modification in the present experiments.

Stated briefly, $2.5-4.0 \mathrm{~mm}$ segments of proximal straight tubules were obtained by gentle teasing from cortical and outer medullary regions of rabbit renal cortex. The dissections were carried out at $0-5^{\circ} \mathrm{C}$ in the $\mathrm{HCO}_{3}-\mathrm{KR}$ bathing media described below. The isolated tubule segments were transferred to a thermoregulated $\left( \pm 0.5^{\circ} \mathrm{C}\right)$ chamber, sucked into holding and collecting pipets, and perfused with a 
microsyringe pump in series with a perfusion pipet advanced approximately $0.2 \mathrm{~mm}$ into the tubule lumen.

The $\mathrm{HCO}_{3}-\mathrm{KR}$ perfusing solutions used in most experiments contained $105 \mathrm{mM} \mathrm{NaCl}, 25 \mathrm{mM} \mathrm{NaHCO}, 10 \mathrm{mM}$ $\mathrm{Na}$ acetate, $4 \mathrm{mM} \mathrm{Na} 2 \mathrm{HPO}_{4} / \mathrm{NaH}_{2} \mathrm{PO}_{4}, 5 \mathrm{mM} \mathrm{KCl}, 1.8 \mathrm{mM}$ $\mathrm{CaCl}_{2}, 1 \mathrm{mM} \mathrm{MgSO}_{4}, 8.3 \mathrm{mM}$ glucose, and $5.0 \mathrm{mM}$ L-alanine; the $\mathrm{HCO}_{3}-\mathrm{KR}$ baths contained, in addition to these constituents, $6.0 \%$ bovine serum albumin. Both solutions were bubbled continuously with $95 \% \quad \mathrm{O}_{2}-5 \% \quad \mathrm{CO}_{2}$. The $\mathrm{Cl}$ $\mathrm{KR} / \mathrm{O}_{2}$ perfusing and bathing media were identical to $\mathrm{HCO}_{3}-\mathrm{KR}$ solutions except that $\mathrm{Cl}^{-}$replaced $\mathrm{HCO}_{3}{ }^{-}$; the $\mathrm{Cl}-\mathrm{KR} / \mathrm{O}_{2}$ solutions were bubbled with $100 \% \quad \mathrm{O}_{2}$ rather than $\mathrm{CO}_{2}$. Other changes in the composition of perfusing and/or bathing solutions are indicated in the text. All solutions were adjusted to $300 \mathrm{mosmol} / \mathrm{liter}, \mathrm{pH}$ 7.4.

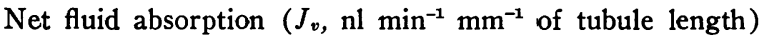
was measured as described previously (1) from the difference between perfusion and collection rates, with exhaustively dialyzed [methoxy- ${ }^{3} \mathrm{H}$ ] inulin as the volume marker; a positive sign for $J_{v}$ denotes volume efflux from lumen to bath. Since the mean internal diameter of these tubules is $22.3 \mu \mathrm{m}$ (1), $J_{v}$ values may be converted from nanoliters $\min ^{-1} \mathrm{~mm}^{-1}$ to $\mathrm{cm}^{3} \mathrm{~s}^{-1} \mathrm{~cm}^{-2}$ by the factor $2.38 \times 10^{-5} \mathrm{~cm}$ $\min \mathrm{mm} \mathrm{nl}^{-1} \mathrm{~s}^{-1}(9)$. The $J_{v}$ measurements in the present experiments were in the range $0.1-0.45 \mathrm{nl} \mathrm{min}^{-1} \mathrm{~mm}^{-1}$ for tubules $2.5-4.0 \mathrm{~mm}$ in length; for isolated proximal convoluted tubules, $J_{v}$ values in the range of $1.0 \mathrm{nl} \mathrm{min}-1 \mathrm{~mm}^{-1}$ have been reported for segments $0.5-1.5 \mathrm{~mm}$ in length (2, $22,23)$. In other words, although $J_{v}$ is smaller for straight tubules than for proximal convolutions, absolute differences between perfusion and collection rates, and hence the precision of $J_{v}$ measurements, are comparable in the two segments.

Since certain of the fluid absorption rates reported in this paper (e.g., Tables V, VI, VIII, and XI) were in the

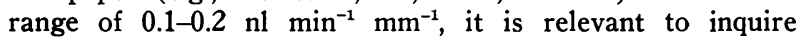
about the extent to which random variations in radioactivity counting might account for such $J_{v}$ values. In the experiments reported in this paper (66 tubules), the mean tubule length was $3.50 \pm 0.07$ (mean $\pm \mathrm{SEM}$ ), the mean perfusion rate was $11.59 \pm 0.25 \mathrm{nl} / \mathrm{min}$, and the mean $\left[{ }^{3} \mathrm{H}\right]$ inulin radioactivity in the perfusing solutions was $28.75 \pm 1.05 \mathrm{cpm} / \mathrm{nl}$. The collected fluid was sampled at 7 - to 10 -min intervals; and, in all cases, perfusing solution standards and collected fluid samples were counted for 10 -min periods. With the same perfusing solutions, the coefficient of variation for the liquid scintillation counter used in our laboratory is, at a maximum, $\pm 0.3 \%$ for a 10 -min counting period.

Accordingly, in an average $3.5-\mathrm{mm}$ tubule perfused for $8 \mathrm{~min}$ at $11.59 \mathrm{nl} / \mathrm{min}$ with a solution containing $28.75 \mathrm{cpm}$ $/ \mathrm{nl}\left[{ }^{3} \mathrm{H}\right]$ inulin, the total radioactivity collected (in the absence of bath leaks) was 26,657 counts $/ 10 \mathrm{~min}$ with an average random variation of \pm 80 counts $/ 10 \mathrm{~min}$. Thus, the random error in estimating perfusion rate would be $11.59 \pm$ $0.035 \mathrm{nl} / \mathrm{min}$, which, for the tubule length of $3.5 \mathrm{~mm}$, could result in errors in $J_{v}$ measurements amounting to approximately $0.01 \mathrm{nl} \mathrm{min} \mathrm{mm}^{-1}$, or about $10 \%$ of the lowest observed $J_{v}$ value significantly different from zero (Table XI, $0.13 \mathrm{nl} \mathrm{min}-1 \mathrm{~mm}^{-1}$ ). Such error in $J_{v}$ determinations would be random, while the results in Table XI, for example, are specific and statistically reliable in paired observations on the same tubule.

Transepithelial electrical potential differences $\left(V_{e}\right.$, in millivolts, lumen with respect to bath) were measured as described previously $(1,9)$ with glass $0.9 \% \mathrm{NaCl} / 4 \%$ agar electrodes placed in both perfusing and bathing solutions.
The electrodes were connected via Tygon tubing (Chamberlain Engineering Corp., Akron, Ohio) filled with $3 \mathrm{M}$ $\mathrm{KCl}$ to calomel half-cells. Since the perfusing and bathing solutions were almost identical in ionic composition for all the experiments reported in this paper, no corrections for liquid junction potentials were necessary. The length constant for the proximal straight tubule is approximately $0.1 \mathrm{~mm}$ (3). Consequently, $V_{e}$ measurements in the present paper provided direct information only about electrical events vicinal to the tip of inner perfusion pipet.

Chloride concentrations in perfusing and collected fluids were measured as described previously (9) with a microtitration method (24). In experiments in which the $\mathrm{Cl}^{-}$ concentration of collected fluid was determined, samples for the measurement of $J_{v}$ were alternated with samples for $\mathrm{Cl}^{-}$ measurement; the latter were stored in glass micropipets between oil columns until the day after the experiment (a representative experiment according to this protocol, described in the Results section, is shown in Table I). All samples of collected fluid were compared to standard solutions with varying $\mathrm{NaCl}$ concentrations but the same concentrations of all other constituents as perfusing solutions. For the sake of uniformity, samples of perfusing solutions were treated in the same manner and also analyzed for $\mathrm{Cl}^{-}$ concentrations with the ultramicro method. Duplicate ultramicro and large sample determinations (with an AmincoCotlove chloride titrator: American Instrument Co., Silver Springs, Md.) of chloride concentrations agreed within $2 \%$.

$\left[{ }^{14} \mathrm{C}\right]$ Acetate fluxes, measuring either the disappearance of tagged acetate from luminal solutions or tagged acetate flux from bath to lumen, were carried out as described previously (1), with 25 or $50 \mu \mathrm{Ci} / \mathrm{ml}$ of isotope (New England Nuclear, Boston, Mass.) in perfusing or bathing solutions, respectively. In luminal efflux experiments, the bath tracer concentration was uniformly less than $1 \%$ of the tracer concentration in the perfusate. In bath-to-lumen tracer fluxes, the tracer concentration in collected tubular fluid was, at a maximum, $4 \%$ of the bath tracer concentration, which was constant. The acetate influx $\left(K_{A 0}{ }^{i}\right)$ and efflux $\left(K_{A c}{ }^{e}\right)$ coefficients, both in centimeters per second, were computed from bath-to-lumen tracer fluxes and luminal tracer effluxes, respectively, as described previously (1). As stressed previously (1), $K_{A c}{ }^{e}$ includes, in principle, terms for passive and active ion transport, exchange diffusion, and metabolic consumption of luminal acetate by tubular epithelial cells.

Acetazolamide and ethoxzolamide in chemically pure form were kindly provided by Dr. T. Maren (University of Florida, Gainesville, Fla.). Other reagents, isotope counting techniques, and chemical determinations were as described previously $(1,9)$. Measurements in a given tubule were used to compute a mean value for that tubule; generally, there were three to four measurements per tubule for a given set of experimental conditions. The mean values for individual tubules (e.g., the representative experiment in Table I) were then used to calculate a mean value \pm SEM for the indicated number of tubules. The experimental results were expressed in this manner. When control and experimental observations were made within the same tubule, $P$ values for mean paired differences were computed from Student's $t$ test by comparing the differences to zero.

\section{RESULTS}

The contribution of $\mathrm{Cl}^{-}$to net anion flux. We noted earlier (1) that in superficial proximal straight tubules perfused and bathed at $37^{\circ} \mathrm{C}$ with $\mathrm{HCO}_{3}-\mathrm{KR}$ solutions, 
the net lumen to bath $\mathrm{Na}^{+}$flux ${ }^{3}\left(J_{\mathrm{Na}}{ }^{\mathrm{net}}\right.$, eq $\left.\min ^{-1} \mathrm{~mm}^{-1}\right)$, computed from the difference between unidirectional lumen to bath and bath to lumen ${ }^{22} \mathrm{Na}^{+}$fluxes, was in close agreement with the value of $\mathrm{J}_{\mathrm{Na}}{ }^{\text {net }}$ predicted from simultaneous measurements of net fluid absorption for an isotonic process. Specifically, in tubules having a

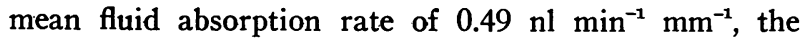
predicted net $\mathrm{Na}^{+}$flux (computed as the product of $J_{0}$ and the $\mathrm{Na}^{+}$concentration in the perfusate) was 65.5 peq $\mathrm{min}^{-1} \mathrm{~mm}^{-1}$ while the observed net $\mathrm{Na}^{+}$flux was $63.8 \mathrm{peq} \mathrm{min}^{-1} \mathrm{~mm}^{-1}$. Based on these results, values for the expected net lumen to bath $\mathrm{Na}^{+}$flux used in this paper were computed as the product of $J_{v}$ and the $\mathrm{Na}^{+}$ concentrations of perfusing solutions.

A representative experiment illustrating the method used for measuring net lumen to bath $\mathrm{Cl}^{-}$flux is presented in Table I. Alternating samples of collected fluid were taken for $J_{v}$ and $\mathrm{Cl}^{-}$determinations. These data were used to compute mean values for $J_{v}$ and collected fluid $\mathrm{Cl}^{-}$concentration in that tubule; the mean perfusion and collection rates for the tubule were computed from the values of these variables measured during the $J_{v}$ periods.

Table II presents the results of five such experiments in as many individual tubules. The mean value for $J_{v}$, $0.38 \mathrm{nl} \min ^{-1} \mathrm{~mm}^{-1}$, was approximately the same as reported previously $(1,9)$, and the $\mathrm{Cl}^{-}$concentration of the collected fluid was $10.9 \pm 1.4 \mathrm{meq} / \mathrm{liter}$ higher than that in the perfusate $(P<0.002)$. The rate of tubular chloride perfusion was computed from the product of the perfusion rate and the perfusate chloride

\footnotetext{
${ }^{3}$ Net ion absorption $\left(J_{1 \text { on }}{ }^{\text {net }}\right)$ in this paper is expressed as peq $\min ^{-1} \mathrm{~mm}^{-1}$ of tubule length. Since the mean internal diameter of these tubules is $22.3 \mu \mathrm{m}$ (1), $J_{1 \text { on }}{ }^{\text {not }}$ may be converted from peq $\mathrm{min}^{-1} \mathrm{~mm}^{-1}$ to neq $\mathrm{s}^{-1} \mathrm{~cm}^{-2}$ of apparent luminal surface area by the factor 0.02381 .
}

TABLE I

A Representative Experiment Measuring the $\mathrm{Cl}^{-}$ Component of Net Anion Flux

\begin{tabular}{ccccc}
\hline Time & $\begin{array}{c}\text { Perfusion } \\
\text { rate }\end{array}$ & $\begin{array}{c}\text { Collection } \\
\text { rate }\end{array}$ & $J$, & {$\left[\mathrm{Cl}^{-}\right]$oolloctod fluid } \\
\hline $\min$ & $n l / m i n$ & $n l / m i n$ & $n l \mathrm{~min}^{-1} \mathrm{~mm}^{-1}$ & $\mathrm{mM}$ \\
$39-49$ & 14.28 & 13.24 & 0.30 & - \\
$49-57$ & - & - & - & 127.0 \\
$57-66$ & 11.91 & 10.29 & 0.46 & - \\
$66-74$ & - & - & - & 121.0 \\
$75-82$ & 13.56 & 12.33 & 0.35 & - \\
$82-91$ & - & - & - & 124.0 \\
$91-100$ & 12.31 & 10.63 & 0.48 & - \\
Mean values & 13.01 & 11.62 & 0.40 & 124.0 \\
\hline
\end{tabular}

Proximal straight tuble segments were perfused and bathed with HCO.-KR buffer solutions at $37^{\circ} \mathrm{C}$. Time represents the time elapsed after sacrifice of the animal. As described previously (1), the perfusion and collection rates were measured from the rates of delivery into the collected fluid of $[$ methoxy-2 $\mathrm{H}]$ inulin and volume, respectively. The chloride concentration of the perfusate, measured as described previously (9) with an ultramicro method (24), was $115 \mathrm{meq} / \mathrm{liter}$.

concentration, and the rate of tubular chloride collection was computed as the product of the collection rate and the chloride concentration in the collected fluid. $J_{\mathbf{C l}^{\text {not }}}$, the net chloride flux from lumen to bath, was expressed as the difference between the rates of $\mathrm{Cl}^{-}$ perfusion and collection per millimeter of tubule length. The last column of Table II shows that $J_{\mathrm{Cl}_{1}}{ }^{\text {net }}$ was $27.5 \pm 2.3 \%$ of the expected $J_{\mathrm{Na}}{ }^{\text {not }}$.

We measured the $\mathrm{Cl}^{-}$concentrations of perfusing and collected fluids for tubules perfused and bathed with $\mathrm{HCO}_{3}-\mathrm{KR}$ solutions at $21^{\circ} \mathrm{C}$, since, under these conditions, $J_{v}$ and $V$ o are both zero $(1,9$; Tables $\mathrm{V}$ and VIII). In five tubules perfused and bathed at $21^{\circ} \mathrm{C}$, the perfusate $\mathrm{Cl}^{-}$concentration was $116.4 \pm 1.6 \mathrm{mM}$, the collected fluid $\mathrm{Cl}^{-}$concentration was $116.2 \pm 1.8 \mathrm{mM}$, and the mean paired difference between these two con-

TABLE II

The $\mathrm{Cl}^{-}$Component of Net Anion Flux

\begin{tabular}{|c|c|c|c|c|c|c|c|c|c|}
\hline \multirow[b]{2}{*}{ Tubule } & \multicolumn{2}{|c|}{ Perfusate } & \multicolumn{2}{|c|}{ Collected fluid } & \multirow[b]{2}{*}{$\Delta\left[\mathrm{Cl}^{-}\right]$} & \multirow[b]{2}{*}{$J_{0}$} & \multirow[b]{2}{*}{$J_{\mathbf{C l}^{\text {net }}}$} & \multirow[b]{2}{*}{$J_{\mathrm{Na}_{2}}^{\text {net }}$} & \multirow[b]{2}{*}{$J_{\mathrm{CI}^{\text {net }}} / J_{\mathrm{N}_{2}}^{\text {not }}$} \\
\hline & {$\left[\mathrm{Cl}^{-}\right]$} & Rate & {$\left[\mathrm{Cl}^{-}\right]$} & Rate & & & & & \\
\hline$m m$ & $m M$ & $n l / \min$ & $m M$ & $n l / \min$ & $m M$ & $n l \min ^{-1} m m^{-1}$ & \multicolumn{2}{|c|}{ peq $\min ^{-1} \mathrm{~mm}^{-1}$} & $\%$ \\
\hline 3.45 & 117.0 & 10.26 & 131.2 & 8.65 & 14.2 & 0.46 & 19.0 & 67.7 & 28.0 \\
\hline 3.25 & 116.0 & 8.62 & 126.3 & 7.67 & 10.3 & 0.29 & 9.6 & 42.7 & 22.4 \\
\hline 2.95 & 115.0 & 11.92 & 122.0 & 10.73 & 7.0 & 0.40 & 21.0 & 58.9 & 35.6 \\
\hline 3.5 & 115.0 & 13.01 & 124.0 & 11.62 & 9.0 & 0.39 & 16.1 & 57.4 & 28.0 \\
\hline 3.6 & 120.0 & 8.81 & 134.5 & 7.54 & 14.0 & 0.35 & 13.0 & 51.5 & 23.3 \\
\hline Mean & 116.6 & & 127.6 & & 10.9 & 0.38 & 15.7 & 55.6 & 27.5 \\
\hline$\pm \mathrm{SEM}$ & \pm 0.9 & & \pm 2.3 & & $\begin{array}{c} \pm 1.4 \\
P<0.002\end{array}$ & \pm 0.03 & \pm 2.0 & \pm 2.0 & \pm 2.3 \\
\hline
\end{tabular}

The data presented are from five experiments at $37^{\circ} \mathrm{C}$, each conducted as outlined in Table $\mathrm{I} . \Delta\left[\mathrm{Cl}^{-}\right]$represents the difference in $\mathrm{Cl}^{-}$concentration between perfused and collected fluids. Net $\mathrm{Cll}^{\text {net }}$ was computed from differences between the rates of $\mathrm{Cl}^{-}$ perfusion and collection. $J_{\mathrm{Na}^{n}}{ }^{\text {net}}$, the expected net $\mathrm{Na}^{+}$flux, was calculated as described in Results. 
TABLE III

Effect of Acetazolamide on $\mathrm{J}_{\mathrm{v}}$ and $\mathrm{V}_{e}: \mathrm{HCO}_{3}{ }^{-} \mathrm{KR}$

Perfusate and Bath

\begin{tabular}{ccc}
\hline Acetazolamide & $J_{v}$ & $V_{\bullet}$ \\
\hline$m M$ & $n l m^{-1} m^{-1} m^{-1}$ & $m V$ \\
0 & $0.26 \pm 0.03$ & $-1.3 \pm 0.20$ \\
0.22 & $0.11 \pm 0.02$ & $-1.6 \pm 0.21$ \\
Mean paired & $0.16 \pm 0.02$ & $0.32 \pm 0.08$ \\
difference & $P<0.001$ & $P<0.01$ \\
& \multicolumn{2}{c}{$(n=10)$} \\
0 & $0.34 \pm 0.03$ & $-0.62 \pm 0.14$ \\
2.25 & $0.18 \pm 0.02$ & $-0.62 \pm 0.11$ \\
Mean paired & $0.16 \pm 0.03$ & $0.00 \pm 0.10$ \\
difference & $P<0.001$ & $P>0.10$ \\
& \multicolumn{2}{c}{$(n=7)$}
\end{tabular}

Proximal straight tubule segments were perfused and bathed with $\mathrm{HCO}_{3}-\mathrm{KR}$ buffer solutions at $37^{\circ} \mathrm{C}$. When present, acetazolamide was added to both perfusate and bath at the indicated concentrations. Paired observations on each tubule were carried out in all instances. All values of $J_{v}$ and $V_{e}$ in the presence or absence of acetazolamide differed from zero at $P<0.001$. The mean perfusion rates for the sets of experiments involving $0.22 \mathrm{mM}$ and $2.25 \mathrm{mM}$ acetazolamide were $12.29 \pm 0.28$ and $11.15 \pm 0.62$, respectively.

centrations was $0.2 \pm 0.1 \mathrm{mM}(P>0.1)$. Thus, we are confident that the rise in tubular fluid concentration at $37^{\circ} \mathrm{C}$ (Table II) was not due to an experimental artifact arising during tubular perfusion.

The effect of carbonic anhydrase inhibitors. It is clear from the results shown in Table II that anions other than $\mathrm{Cl}^{-}$were preferentially absorbed with $\mathrm{Na}^{+}$. Accordingly, we assessed the effects of carbonic anhydrase inhibitors on $J_{v}$ and $V_{0}$ (Tables III and IV) in paired control and experimental (i.e., in the presence of acetazolamide or ethoxzolamide) measurements in each of the tubules tested. The order in which observations were made was not varied; rather, one or the other inhibitor was always added after control observations. However, the $J_{v}$ and $V$ o measurements in the presence of acetazolamide or ethoxzolamide were completed within $100 \mathrm{~min}$ after initiating tubule perfusion, and our earlier observations (1) indicate that, within this time span, values for $J_{v}$ and $V_{0}$ in a given tubule perfused and bathed with $\mathrm{HCO}_{3}-\mathrm{KR}$ solutions are stable.

Table III illustrates the effects of adding the relatively hydrophilic agent $(15,16)$ acetazolamide to both perfusing and bathing solutions. At $0.22 \mathrm{mM}$ acetazolamide, $J_{v}$ fell approximately $61 \%$, while $V$. rose slightly. The former seems to be the maximal degree to which the carbonic anhydrase inhibitor reduced fluid absorption from tubules exposed to symmetrical $\mathrm{HCO}_{3}-\mathrm{KR}$ solutions, since at approximately 10 -fold higher con- centrations of acetazolamide, $2.25 \mathrm{mM}, J_{\bullet}$ was inhibited $47 \%$ and $V$ e was unchanged. In like manner, Table VIII (cf. below) shows that addition of $0.16 \mathrm{mM}$ ethoxzolamide, a relatively lipophilic agent $(15,16)$, to bathing media inhibited $J_{v}$ by approximately $40 \%$. These observations are comparable to the effects of acetazolamide on fluid absorption from proximal tubules during in vivo micropuncture $(14,17-19)$.

It seems reasonable to surmise from these data that both acetazolamide (Table III) and ethoxzolamide (Table VIII) inhibited carbonic anhydrase-dependent $\mathrm{HCO}^{-}$ absorption $(12-20)$. But it is possible that the effects of these agents on $J_{v}$ were nonspecific. For example, Grantham et al. observed (25) that the diuretics acetazolamide, chlorothiazide, and furosemide each reduced fluid absorption in isolated rabbit proximal tubules by $30-80 \%$. The recent observations of Burg et al. indicate clearly that diuretics such as mersalyl (26), furosemide (27), and ethacrynic acid (28) inhibit primarily active $\mathrm{Cl}^{-}$absorption in isolated segments of the thick ascending limb of Henle's loop. Since the rabbit proximal straight tubule secretes organic acids $(29,30)$, it might therefore be argued (25) that the effects of acetazolamide and ethoxzolamide on net fluid absorption in these tubules (Tables III, VIII) were the consequence of fluid secretion coupled to net bath to lumen flux of these agents. This possibility was not evaluated explicitly, since we did not measure fluxes of these diuretics. However, Table IV shows that when the tubules were

TABLE IV

Effect of Carbonic Anhydrase Inhibitors on $J_{v}$ and $V_{e}$ : $\mathrm{Cl}-\mathrm{KR} / \mathrm{O}_{2}$ Perfusate and Bath

\begin{tabular}{lcc}
\multicolumn{1}{c}{ Inhibitor } & $J_{v}$ & $V \cdot$ \\
\hline & $n l$ min $^{-1} \mathrm{~mm}^{-1}$ & $m V$ \\
None & $0.37 \pm 0.13$ & $-0.88 \pm 0.05$ \\
$0.22 \mathrm{mM}$ acetazolamide & $0.36 \pm 0.05$ & $-0.70 \pm 0.11$ \\
Mean paired difference & $0.01 \pm 0.02$ & $0.18 \pm 0.15$ \\
& $P>0.5$ & $P>0.5$ \\
None & \multicolumn{2}{c}{$(n=5)$} \\
0.16 $\mathrm{mM}$ ethoxzolamide & $0.35 \pm 0.02$ & $-1.00 \pm 0.1$ \\
Mean paired difference & $0.03 \pm 0.01$ & $0.07 \pm 0.08$ \\
& $P>0.05$ & $P>0.05$ \\
& \multicolumn{2}{c}{$(n=4)$}
\end{tabular}

Proximal straight tubules were perfused and bathed with $\mathrm{Cl}-\mathrm{KR} / \mathrm{O}_{2}$ buffer solutions at $\mathrm{pH} 7.4$ bubbled with $100 \% \mathrm{O}_{2}$. When present, acetazolamide was added to both perfusing and bathing fluids, while ethoxzolamide was added only to bathing solutions. In all instances, paired observations on each tubule were carried out. In the experiments with acetazolamide and ethoxzolamide, the mean perfusion rates were $11.85 \pm 0.91$ and $11.45 \pm 0.45$, respectively. 
perfused and bathed with $\mathrm{Cl}-\mathrm{KR} / \mathrm{O}_{2}$ solutions exposed to $100 \% \quad \mathrm{O}_{2}$ rather than $95 \% \quad \mathrm{O}_{2}-5 \% \quad \mathrm{CO}_{2}$ (conditions which, for these tubules, give comparable values for $J_{v}$; ref. 1), neither $0.22 \mathrm{mM}$ acetazolamide nor 0.16 $\mathrm{mM}$ ethoxzolamide had a detectable effect on $J_{v}$. Consequently it is reasonable to infer that the inhibition of fluid absorption produced by these agents (Tables III, VIII) was due to decrements in the rate of $\mathrm{CO}_{2}$ hydration. According to this view, the results in Tables III, and VIII indicate that $40-60 \%$ of the expected net $\mathrm{Na}^{+}$flux in these tubules was coupled to $\mathrm{CO}_{2}$ and carbonic anhydrase-sensitive $\mathrm{HCO}_{3}^{-}$absorption.

The acetazolamide-insensitive moiety of $J_{v}$. It is well known that $40-50 \%$ of proximal tubular $\mathrm{HCO}_{3}^{-}$ absorption continues after virtually complete (i.e., greater than $99.99 \%$ ) inhibition of renal carbonic anhydrase activity by acetazolamide (12-20). Thus we examined in part the acetazolamide-insensitive fraction of fluid absorption in these tubules. Table $\mathrm{V}$ indicates, in accord with earlier observations (1), that cooling from $37^{\circ}$ to $21^{\circ} \mathrm{C}$ in random paired experiments reduced the acetazolamide-insensitive moiety of net fluid absorption in tubules exposed to symmetrical

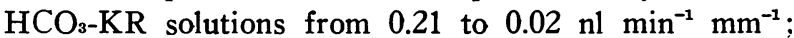
the former differed significantly from zero $(P<0.001)$, while the latter was indistinguishable from zero $(P$ $>0.5$ ).

We also assessed the magnitude of net $\mathrm{Cl}^{-}$flux with respect to the expected net $\mathrm{Na}^{+}$flux in the presence of $2.25 \mathrm{mM}$ acetazolamide (Table VI). To exclude possible contributions of glucose (31), alanine, or acetate absorption (Tables VII-IX) to acetazolamide-insensitive fluid absorption, the $\mathrm{HCO}_{s}-\mathrm{KR}$ perfusates, but
TABLE V

Effect of Cooling on the Acetazolamide-Insensitive Moiety of $J_{v}$

\begin{tabular}{ccc}
\hline Temperature & Acetazolamide & $J_{v}$ \\
\hline${ }^{\circ} \mathrm{C}$ & $m M$ & $n l \min ^{-1} \mathrm{~mm}^{-1}$ \\
37 & 2.25 & $0.20 \pm 0.03$ \\
21 & 2.25 & $0.02 \pm 0.01$ \\
& & $0.18 \pm 0.03$ \\
Mean paired difference & $P<0.02$ \\
& & $(n=4)$
\end{tabular}

Proximal straight tubules were perfused and bathed with $\mathrm{HCO}_{3}-\mathrm{KR}$ solutions in the presence of $2.25 \mathrm{mM}$ acetazolamide in both solutions. $J_{v}$ and $V_{e}$ were measured at $37^{\circ}$ and $21^{\circ} \mathrm{C}$. In all instances, paired observations on each tubule were carried out in random order. The values of $J_{v}$ at $37^{\circ} \mathrm{C}$ differed from zero at $P<0.001$, while the values of $J_{v}$ at $21^{\circ} \mathrm{C}$ were indistinguishable from zero $(P>0.5)$. The mean perfusing rate was $9.64 \pm 0.63$

not the baths, used in these experiments were modified: glucose and alanine were replaced isosmotically with urea; and acetate was replaced isosmotically with isethionate, a highly impermeant anion ( $P_{\text {isethionate }}$ in these tubules is $0.023 \mu \mathrm{m} / \mathrm{s}$; [9]). As is shown in Table $\mathrm{XI}$, luminal isethionate, sulfate, and phosphate, in the absence of luminal $\mathrm{Cl}^{-}$, acetate, glucose, alanine, and $\mathrm{HCO}_{3}{ }^{-}$concentrations greater than $3.8 \mathrm{mM}$, are unable to support rates of fluid absorption distinguishable from zero. And our prior observations have shown that in these tubules, oppositely directed transepithelial concentration gradients for urea and alanine plus glucose (specifically, urea in luminal solutions and glucose plus

TABLE VI

The $\mathrm{Cl}^{-}$Component of Net Anion Flux for the Acetazolamide-Insensitive Moiety of $J_{\text {v }}$

\begin{tabular}{|c|c|c|c|c|c|c|c|c|c|}
\hline \multirow[b]{2}{*}{ Tubule } & \multicolumn{2}{|c|}{ Perfusate } & \multicolumn{2}{|c|}{ Collected fluid } & \multirow[b]{2}{*}{$\Delta\left[\mathrm{Cl}^{-}\right]$} & \multirow[b]{2}{*}{$J_{0}$} & \multirow[b]{2}{*}{$J_{\mathrm{Cl}^{\text {not }}}$} & \multirow[b]{2}{*}{$J_{\mathrm{Na}_{\mathrm{a}} \mathrm{a}^{\mathrm{not}}}$} & \multirow[b]{2}{*}{$J \mathrm{CP}^{\text {net }} / J_{\mathrm{N}_{2}{ }^{\text {net }}}$} \\
\hline & {$\left[\mathrm{Cl}^{-}\right]$} & Rate & {$\left[\mathrm{Cl}^{-}\right]$} & Rate & & & & & \\
\hline$m m$ & $m M$ & $n l / m i n$ & $m M$ & $n l / m i n$ & $m M$ & $n l \min ^{-1} m^{-1}$ & \multicolumn{2}{|c|}{ peq $\min ^{-1} m m^{-1}$} & $\%$ \\
\hline 2.34 & 117.5 & 8.08 & 120 & 7.54 & 2.5 & 0.26 & 19.1 & 38.2 & 50.0 \\
\hline 3.7 & 118.0 & 8.12 & 117.7 & 7.60 & -0.3 & 0.14 & 18.2 & 20.6 & 88.3 \\
\hline 3.4 & 118.8 & 9.45 & 122.6 & 8.80 & 3.8 & 0.18 & 12.9 & 26.4 & 48.9 \\
\hline 3.7 & 116.0 & 12.50 & 120.5 & 11.20 & 4.5 & 0.35 & 27.8 & 51.8 & 53.6 \\
\hline 3.9 & 116.0 & 15.14 & 116.7 & 14.72 & 0.7 & 0.11 & 10.1 & 16.2 & 62.3 \\
\hline 3.8 & 120.5 & 10.35 & 120.6 & 9.96 & 0.1 & 0.10 & 12.1 & 14.7 & 82.3 \\
\hline Mean & 117.8 & 10.60 & 119.7 & 9.97 & 1.88 & 0.19 & 16.7 & 28.0 & 64.2 \\
\hline \pm SEM & \pm 0.7 & & \pm 0.9 & & \pm 0.82 & \pm 0.04 & \pm 2.6 & \pm 5.9 & \pm 7.0 \\
\hline & & & & & $P>0.05$ & & & & \\
\hline
\end{tabular}

$\mathrm{Cl}^{-}$concentrations of perfused and collected fluids were measured for tubules perfused and bathed at $37^{\circ} \mathrm{C}$ with solutions containing $2.25 \mathrm{mM}$ acetazolamide. $\Delta\left[\mathrm{Cl}^{-}\right], J_{\mathrm{Cl}}{ }^{\text {net }}$, and the expected $J_{\mathrm{Na}^{\text {net }}}$ were computed as described for Table II. The $\mathrm{HCO}_{3}-\mathrm{KR}$ perfusates used in these experiments were modified in the following manner: glucose and alanine were replaced isosmotically with urea, and acetate was replaced by isethionate. The bath was unmodified $\mathrm{HCO}_{3}-\mathrm{KR}$. The values for $J_{v}$ were uniformly different from zero $(P>0.001)$. 
alanine in bathing solutions) do not result in $J_{v}$ values different from zero (9). Thus, in Table VI, $\mathrm{HCO}_{3}^{-}$ and $\mathrm{Cl}^{-}$were the only potentially suitable counterions in the perfusing solutions for expected net $\mathrm{Na}^{+}$flux resulting in rates of fluid absorption significantly different from zero.

The experimental results, shown in Table VI, illustrate several noteworthy characteristics. First, in the presence of acetazolamide (and in the absence of luminal acetate, glucose, and alanine), increases in tubular fluid $\mathrm{Cl}^{-}$concentrations (e.g., see Table II) were blunted. In Table VI, the $\mathrm{Cl}^{-}$concentration of collected fluid was $119.7 \pm 0.9 \mathrm{mM}$, i.e., negligibly greater (1.88 $\pm 0.82 \mathrm{mM} ; P>0.05)$ than that in the perfusate. Second, the observed net $\mathrm{Cl}^{-}$flux accounted for approximately two-thirds of the expected net $\mathrm{Na}^{+}$flux. By exclusion, we argue that approximately one third of the expected net $\mathrm{Na}^{+}$flux was accompanied by $\mathrm{HCO}_{3}{ }^{-}$, although the acetazolamide concentration used in these experiments, $2.25 \mathrm{mM}$, was ten times that required for maximal inhibition of fluid absorption from symmetrical $\mathrm{HCO}_{8}-\mathrm{KR}$ solutions (Table III). Finally, it is interesting to note that the mean value SEM for the acetazolamide-insensitive component of fluid absorption listed in Table VI did not differ significantly $(P>0.5)$ from the comparable value of $J_{v}$ at $37^{\circ} \mathrm{C}$ shown in Table V. One cannot infer explicitly from this that the temperature-dependent, acetazolamide-insensitive moiety of fluid absorption in Table V occurred independently of luminal glucose, alanine, or acetate, since the experiments in Tables V and VI were carried out on different tubules. However, Table VI indicates per se that acetazolamide-insensitive ion and fluid transport occurred in these tubules in the presence of luminal $\mathrm{Cl}^{-}$and $\mathrm{HCO}_{3}^{-}$and in the absence of either luminal glucose,

\section{TABLE VII}

Acetate Influx and Efflux Coefficients

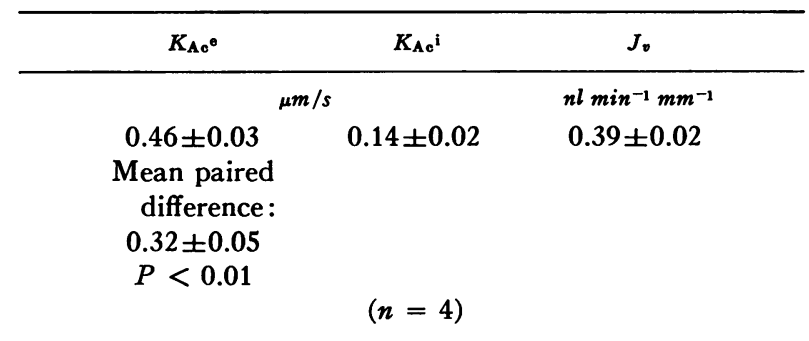

Efflux $\left(K_{\mathbf{A c}}{ }^{\mathrm{e}}\right)$ and influx $\left(K_{\mathbf{A c}}{ }^{i}\right)$ coefficients for acetate were measured as described in Methods from luminal disappearance rates and bath to lumen fluxes, respectively, of $\left[{ }^{14} \mathrm{C}\right]$ acetate at $37^{\circ} \mathrm{C}$. The perfusing and bathing solutions were standard $\mathrm{HCO}_{3}-\mathrm{KR}$ buffers containing $10 \mathrm{mM}$ acetate. $K_{\mathrm{Ac}}{ }^{\mathrm{e}}$ and $K_{\mathrm{Ac}}{ }^{\mathrm{i}}$ were measured in each tubule; the order in which $K_{\mathrm{Ac}}{ }^{\mathrm{e}}$ and $K_{\mathrm{Ac}^{\mathrm{i}}}{ }^{\mathrm{i}}$ were measured was varied at random among the individual tubules. The mean perfusing rate was $8.89 \pm 2.24$.
TABLE VIII

Effect of Cooling or Carbonic Anhydrase Inhibition on the Acetate Efflux Coefficient

\begin{tabular}{cccc}
\hline $\begin{array}{c}\text { Tempera- } \\
\text { ture }\end{array}$ & $\begin{array}{c}\text { Ethoxzol- } \\
\text { amide }\end{array}$ & $K_{\mathbf{A c}^{\circ}}$ & $J_{\boldsymbol{v}}$ \\
\hline${ }^{\circ} \mathrm{C}$ & $m M$ & $\mu m / s$ & $n l$ min $^{-1} \mathrm{~mm}^{-1}$ \\
37 & 0 & $0.40 \pm 0.02$ & $0.32 \pm 0.03$ \\
21 & 0 & $0.18 \pm 0.02$ & $0.01 \pm 0.01$ \\
Mean paired difference & $0.22 \pm 0.03$ & $0.31 \pm 0.03$ \\
& & $P<0.001$ & $P<0.001$ \\
37 & 0 & \multicolumn{2}{c}{$(n=6)$} \\
37 & 0.16 & $0.44 \pm 0.02$ & $0.41 \pm 0.03$ \\
Mean paired difference & $0.06 \pm 0.03$ & $0.25 \pm 0.04$ \\
& & $P>0.5$ & $P<0.03$ \\
& & \multicolumn{2}{c}{$(n=5)$} \\
\hline
\end{tabular}

$K_{\mathrm{Ac}}{ }^{\mathrm{e}}$ and $J_{v}$ were measured as described in Table VIII for tubules perfused and bathed with $\mathrm{HCO}_{3}-\mathrm{KR}$ solutions. In the upper part of the table, the effect of reducing temperature from $37^{\circ}$ to $21^{\circ} \mathrm{C}$ was examined; the order in which experiments was carried out was varied at random. In the lower part of the table, the effect of adding $0.16 \mathrm{mM}$ ethoxzolamide to the bathing solutions was examined; in all cases, control observations preceded those in the presence of ethoxzolamide. Paired observations on the same tubule were carried out in all instances. In the experiments involving cooling, the mean perfusion rate was $11.56 \pm 0.82$; in the experiments with ethoxzolamide, the mean perfusion rate was $11.78 \pm 0.73$.

alanine, and acetate, or oppositely directed transepithelial gradients for relatively permeant and impermeant anions, such as $\mathrm{Cl}^{-}$and $\mathrm{HCO}_{3}^{-}$, respectively (9).

$\left[{ }^{14} \mathrm{C}\right]$ Acetate flux coefficients. Table VII shows the results of experiments designed to measure the flux coefficients for $\left[{ }^{14} \mathrm{C}\right]$ acetate. The influx coefficient was computed, from expressions presented previously (1), from the appearance rate of $\left[{ }^{14} \mathrm{C}\right]$ acetate in luminal solutions. In other words, $K_{\mathbf{A c}}{ }^{1}$ represents the bath-tolumen acetate flux coefficient. On the other hand, $K_{\mathrm{Ac}}{ }^{\mathrm{e}}$ was calculated, as described previously (1), from the disappearance rates of $\left[{ }^{14} \mathrm{C}\right]$ acetate from luminal solutions. Thus, $K_{\mathbf{A c}}{ }^{\bullet}$ is a luminal efflux coefficient rather than a unidirectional lumen-to-bath flux coefficient, and may include not only terms for passive and/or active $\left[{ }^{14} \mathrm{C}\right]$ acetate flux from lumen to bath, and exchange diffusion of acetate, but also cellular consumption of luminal acetate (1), a phenomenon recently proposed on the basis of proximal tubular micropuncture studies in the rat to account for net luminal efflux of the organic anion lactate (32).

Table VII shows that, in random paired observations in four tubules, $K_{\Delta \mathrm{Ac}}{ }^{\circ}$ was approximately three times greater than $K_{\Delta c^{1}}{ }^{1}$, the mean paired difference between 
these values being $0.32 \pm 0.05(P<0.01)$. Table VIII shows that, in paired observations, cooling from $37^{\circ}$ to $21^{\circ} \mathrm{C}$ reduced $K_{\mathrm{Ac}}{ }^{\mathrm{e}}$ more than twofold, while 0.16 $\mathrm{mM}$ ethoxzolamide in the bath reduced fluid absorption by approximately $40 \%$ (cf. also Table III) but had no effect on $K_{\mathbf{A c}}{ }^{\mathrm{e}}$. We also assessed directly the effects of $\mathrm{CO}_{2}$ omission on $K_{\mathrm{Ac}}{ }^{e}$. In five tubules, random paired measurements of $K_{\mathrm{Ac}} \mathrm{e}^{\mathrm{e}}$ were made under the following conditions: either when the perfusate and bath each contained $\mathrm{HCO}_{3}-\mathrm{KR}$ bubbled at $\mathrm{pH} 7.4$ with $95 \% \mathrm{O}_{2}-$ $5 \% \mathrm{CO}_{2}$ at $37^{\circ} \mathrm{C}$; or when the perfusate and bath each contained $\mathrm{Cl}-\mathrm{KR} / \mathrm{O}_{2}$ bubbled at $\mathrm{pH} 7.4$ with $\mathrm{O}_{2}$ at $37^{\circ} \mathrm{C}$. The mean paired difference for $K_{\mathrm{Ac}} \mathrm{e}^{\mathrm{e}}$ under these two conditions was $-0.11 \pm 0.05(P>0.2)$. These data, taken together with the results in Tables VII and VIII, indicate clearly that $K_{\mathrm{Ac}}{ }^{\mathrm{e}}$ exceeded $K_{\mathrm{Ac}}{ }^{2}$, and that the difference between $K_{\mathrm{Ac}}{ }^{\mathrm{e}}$ and $K_{\mathrm{Ac}}{ }^{1}$ was temperature-dependent but unaffected either by concentrations of ethoxzolamide sufficient to inhibit fluid absorption or by exclusion of $\mathrm{CO}_{2}$ and $\mathrm{HCO}_{3}{ }^{-}$from the system.

The contribution of luminal acetate efflux to fluid absorption. Since the $\mathrm{pK}$ of acetic acid is 4.7 , the ratio of acetate anion to acetic acid, in the $\mathrm{pH}$ range $6.6-7.4$, varies between 80 and 500. Thus, regardless of the molecular events responsible for the fact that $K_{\mathbf{A c}}{ }^{\circ}$ exceeded $K_{\mathrm{Ac}}{ }^{1}$ (Tables VII and VIII), it is clear that net disappearance of acetate from luminal fluids was accompanied by net cation flux from lumen to bath and by net fluid absorption. We were not able to measure chemically the content of acetate in collected fluids. Accordingly, net luminal acetate effluxes could not be computed from the experiments shown in Tables VII and VIII for the following reasons. First, the results in Table II indicate that tubular fluid $\mathrm{Cl}^{-}$concentrations rose during net fluid absorption; consequently, the acetate concentration in tubular fluid may not have been constant. Second, during the luminal $\left[{ }^{14} \mathrm{C}\right]$ acetate efflux experiments shown in Tables VII and VIII, $10 \mathrm{mM}$ unlabeled acetate was present in the bathing solutions. Since bath to lumen flux of unlabeled acetate could have reduced the $\left[{ }^{14} \mathrm{C}\right]$ acetate specific activity (counts per minute $\left[{ }^{14} \mathrm{C}\right]$ acetate per mole unlabeled acetate) in luminal solutions, the $\left[{ }^{14} \mathrm{C}\right]$ acetate concentration of collected fluid could not be used to compute the unlabeled acetate concentration of collected fluid.

To circumvent these difficulties, we measured luminal effluxes of $\left[{ }^{14} \mathrm{C}\right]$ acetate in experiments in which isethionate replaced acetate in $\mathrm{HCO}_{3}-\mathrm{KR}$ bathing solutions. Table IX presents the results of a series of experiments in which random paired measurements of $K_{\mathrm{Ac}}{ }^{\circ}$ and $J_{\mathrm{v}}$ were carried out either in the presence or absence of acetate in the bathing solutions. With the latter exception, the experimental conditions were identical to those used for assessing simultaneously net fluid absorption and net $\mathrm{Na}^{+}$flux (1), net fluid absorption and net $\mathrm{Cl}^{-}$
TABLE IX

Effect of Omitting Acetate from the Bath on $K_{A c}{ }^{\bullet}$ and $J_{v}$

\begin{tabular}{ccc}
\hline Bath acetate & $K_{\mathrm{Ac}^{\mathrm{e}}}$ & $J_{v}$ \\
\hline$m M$ & $\mu m / \mathrm{s}$ & $n l \mathrm{~min}^{-1} \mathrm{~mm}^{-1}$ \\
10 & $0.34 \pm 0.01$ & $0.32 \pm 0.04$ \\
0 & $0.37 \pm 0.02$ & $0.31 \pm 0.04$ \\
Mean paired & $0.03 \pm 0.01$ & $-0.01 \pm 0.01$ \\
difference & $P>0.5$ & $P>0.5$ \\
& & $(n=5)$ \\
\hline
\end{tabular}

$K_{\mathrm{Ac}}{ }^{\mathrm{e}}$ and $J_{v}$ were measured as described in Table VIII from the disappearance rates of $\left[{ }^{14} \mathrm{C}\right]$ acetate from luminal fluids in tubules perfused with standard $\mathrm{HCO}_{3}-\mathrm{KR}$ buffers containing $10 \mathrm{mM}$ acetate. The bathing solutions were $\mathrm{HCO}_{3}$-KR buffers containing either $10 \mathrm{mM}$ or zero acetate. In the latter case, acetate was replaced by $10 \mathrm{mM}$ isethionate. Paired observations at zero and $10 \mathrm{mM}$ acetate in the bath were carried out in each of the five tubules; the order in which acetate was omitted from the bath was varied at random among the five tubules. The mean perfusing rate was $11.72 \pm 0.98$.

flux (Table II), net fluid absorption and the acetate influx and efflux coefficients (Table VII), and the effects of carbonic anhydrase inhibitors on net fluid absorption and transepithelial voltages (Table IV). The results in Table IX show clearly that, within the limits of experimental error, neither $K_{\mathbf{A c}}{ }^{\bullet}$ nor $J_{v}$ was affected by replacing acetate in the bath with isethionate. Specifically, the mean paired differences for $K_{\mathbf{A c}}{ }^{e}$ and $J_{v}$ in the presence and absence of $10 \mathrm{mM}$ bath acetate were $+0.03 \pm 0.02(P>0.5)$ and $-0.01 \pm 0.01 \quad(P>0.5)$, respectively.

Three issues relating to the results in Table IX are particularly interesting First, since $K_{\mathrm{Ac}}{ }^{\circ}$ was unaffected by removal of bath acetate, it is improbable that acetate exchange diffusion occurred to a detectable degree. Second, $K^{1}$ isethionate, the bath-to-lumen flux constant for isethionate in these tubules, is $0.023 \mu \mathrm{m} / \mathrm{s}$ (9), i.e., 7 and 23 times smaller than $K_{\mathbf{A c}}{ }^{1}$ or $K_{\mathbf{A c}}{ }^{\mathrm{e}}$, respectively (Table VII); thus, it seems unlikely that any appreciable electrically silent exchange of luminal acetate for bath isethionate occurred in the experiments shown in Table IX. Finally, there is compelling experimental evidence that bulk-phase unstirred layer effects do not complicate flux measurements with isolated perfused renal tubules $(9,33,34)$. The latter implies that, in the experiments recorded in Table IX, acetate accumulation in the bath could not have significantly affected the unidirectional efflux of $\left[{ }^{14} \mathrm{C}\right]$ acetate from luminal solutions.

Given these assmptions, it seems reasonable to infer that the $K_{\Delta c^{e}}{ }^{e}$ measurements in the absence of bathing solution acetate (Table IX) may be used to calculate the net efflux - or disappearance-of acetate from luminal solutions, at least for these particular conditions. 
The specific activity $X_{\mathbf{A c}}{ }^{p}$ (in counts per minute per mole) of acetate in the perfusate is :

$$
X_{\mathbf{A c}^{\mathrm{p}}}=\frac{[\mathrm{Ac}]_{\mathrm{p}}{ }^{*}}{[\mathrm{Ac}]_{\mathrm{p}}}
$$

where $[A c]_{p} *$ and $[A c]_{p}$ are, respectively, the concentrations of labeled $\left(\left[{ }^{14} \mathrm{C}\right]\right.$ acetate counts per minute per milliliter) and unlabeled (moles acetate per milliliter) species in the perfusate. In the absence of back flux of unlabeled acetate from bath to lumen, $X_{\mathrm{Ac}}{ }^{\mathrm{p}}$ equals $X_{\mathrm{Ac}}{ }^{\text {er }}$ (counts per minute per mole), the specific activity of acetate in collected fluid, and [Ac] er (moles per milliliter), the unlabeled acetate concentration in collected fluid, is given by

$$
[\mathrm{Ac}]_{\mathrm{ef}}=\frac{[\mathrm{Ac}]_{\mathrm{ef}}{ }^{*}}{[\mathrm{Ac}]_{\mathrm{p}}{ }^{*}}[\mathrm{Ac}]_{\mathrm{p}}
$$

where $[\mathrm{Ac}]_{\mathrm{er}} *$ and $[\mathrm{Ac}]_{\mathrm{er}}$ are the concentrations of the labeled (counts per minute $\left[{ }^{14} \mathrm{C}\right]$ acetate per milliliter) and unlabeled (moles acetate per milliliter) species in the collected fluid, respectively.

Table $\mathrm{X}$ shows that [Ac] es, computed according to Eq. 2 from the $\left[{ }^{14} \mathrm{C}\right]$ acetate efflux data in Table IX with no acetate in the bathing media, was $5.91 \pm 0.77$ $\mathrm{mM}$. $[\overline{\mathrm{Ac}}]$, the arithmetic mean of $[\mathrm{Ac}]_{\mathrm{er}}$ and $[\mathrm{Ac}]_{\mathrm{p}}$, was $8.15 \mathrm{mM}$, and $J_{\Delta c^{n}}{ }^{\text {net }}$, computed as $(1,9)$

$$
J_{\mathrm{Ac}}{ }^{\mathrm{net}}=K_{\mathbf{A c}}{ }^{\mathrm{e}}[\overline{\mathrm{Ac}}]
$$

(with the mean value for $K_{\mathbf{A c}}{ }^{\mathrm{e}}$ in Table IX in the absence of acetate in bathing media) was 0.301 neq s $\mathrm{cm}^{-2}$ or 12.6 peq $\mathrm{min}^{-1} \mathrm{~mm}^{-1}$. In other words, for these conditions, net luminal efflux of acetate accounted for approximately $27.5 \%$ of the expected net $\mathrm{Na}^{+}$absorption.

Finally, we evaluated directly whether luminal acetate alone could support net ion and fluid absorption

TABLE X

An Acetate Contribution to Net Cation Flux

\begin{tabular}{ccccc}
\hline$[\mathrm{Ac}]_{\mathrm{el}}$ & {$[\overline{\mathrm{Ac}}]$} & $J_{\mathrm{Ao}^{\mathrm{net}}}$ & $J_{\mathrm{Na}^{\mathrm{net}}}$ & $J_{\mathrm{Ae}^{\mathrm{not}} / J_{\mathrm{Na}^{\mathrm{net}}}}$ \\
\hline$m M$ & \multicolumn{4}{c}{$\mathrm{peq} / \mathrm{min} / \mathrm{mm}$} \\
$5.91 \pm 0.77$ & 8.15 & 12.6 & 45.8 & 2.75 \\
& $(n=5)$ & & \\
\hline
\end{tabular}

$[\mathrm{Ac}]_{\mathrm{ef}}$, the mean $\pm \mathrm{SEM}$ for the acetate concentration in collected fluid, was computed according to eq. 2 with the luminal $\left[{ }^{14} \mathrm{C}\right]$ acetate efflux data listed in Table IX for the case of zero acetate in the bathing media. $[\overline{\mathrm{Ac}}]$, the mean luminal acetate for these conditions, was taken to be the arithmetic mean of $10 \mathrm{mM} \mathrm{Ac}$, the acetate concentration in perfusing solutions, and $[\mathrm{Ac}]_{\mathrm{ef}}$. $J_{\mathrm{Ac}_{0}}{ }^{\mathrm{net}}$, the net rate of luminal acetate efflux for these conditions, was computed as described previously (1) from the product $K_{\mathrm{Ao}}{ }^{\circ}[\overline{\mathrm{Ac}}]$, with the $K_{\mathrm{Ac}}{ }^{\circ}$ value listed in Table IX for the case of zero bath acetate.

\begin{tabular}{|c|c|c|c|}
\hline$\underset{\text { perfusate }}{[\mathrm{Ac}]}$ & $\begin{array}{c}\text { Tempera- } \\
\text { ture }\end{array}$ & $J_{v}$ & $\Delta J_{v}$ \\
\hline$m M$ & ${ }^{\circ} \mathrm{C}$ & \multicolumn{2}{|c|}{$n l \min ^{-1} m^{-1}$} \\
\hline \multirow[t]{2}{*}{0} & 37 & $\begin{array}{c}-0.04 \pm 0.02 \\
P>0.5\end{array}$ & \\
\hline & & & $\begin{array}{l}0.17 \pm 0.05 \\
P<0.002\end{array}$ \\
\hline \multirow[t]{2}{*}{10} & 37 & $\begin{array}{c}+0.13 \pm 0.04 \\
P<0.002\end{array}$ & \\
\hline & & & $\begin{array}{l}0.16 \pm 0.04 \\
P<0.002\end{array}$ \\
\hline 10 & 21 & $\begin{array}{l}-0.04 \pm 0.03 \\
P>0.5\end{array}$ & \\
\hline
\end{tabular}

TABLE XI

Support of Fluid Absorption by Luminal Acetate

$\mathrm{NaCl}$ and $\mathrm{NaHCO}_{3}$ in the $\mathrm{HCO}_{3}-\mathrm{KR}$ perfusing solutions were uniformly replaced by $\mathrm{Na}$ isethionate, and alanine and glucose were isosmotically replaced with urea. $\mathrm{Na}$ isethionate also replaced $\mathrm{Na}$ acetate when the perfusing acetate was zero. $\mathrm{Na}$ isethionate replaced $\mathrm{NaCl}$ in the $\mathrm{HCO}_{3}-\mathrm{KR}$ bathing solutions. In all solutions, $\mathrm{K}^{+}$and $\mathrm{Ca}^{++}$were present as sulfate rather than $\mathrm{Cl}^{-}$salts, and all solutions were bubbled with $95 \%$ $\mathrm{O}_{2}-5 \% \mathrm{CO}_{2}$. The final $\mathrm{pH}$ of the bathing solutions was 7.4. The final $\mathrm{pH}$ of the perfusing solutions was 6.6 , which corresponds to an $\mathrm{HCO}_{3}{ }^{-}$concentration of $3.8 \mathrm{mM}$. In each of the five tubules studied, $J_{v}$ was measured under each of the indicated experimental conditions. The order in which the various measurements were carried out was made random among individual tubules. The $P$ values under $J_{v}$ values indicate the levels at which these values differed from zero. Mean paired differences and $P$ values for these differences are listed in the $\Delta J_{v}$ column. The mean perfusing rate was $11.76 \pm 1.04$.

(Table XI). In these experiments, the $\mathrm{HCO}_{3}-\mathrm{KR}$ perfusing solutions were modified by isosmotic replacement of $\mathrm{HCO}_{3}^{-}$and $\mathrm{Cl}^{-}$with isethionate, isosmotic replacement of glucose and alanine with urea, and, when acetate was excluded, isosmotic replacement of the latter with isethionate. In the $\mathrm{HCO}_{3}-\mathrm{KR}$ bathing solutions, isethionate replaced acetate. And, in both perfusing and bathing solutions, $\mathrm{K}^{+}$and $\mathrm{Ca}^{++}$were present as sulfate rather than chloride salts. The final $\mathrm{pHs}$ of the bathing and perfusing solutions, all bubbled with $95 \% \quad \mathrm{O}_{2}-5 \%$ $\mathrm{CO}$ were 7.4 and 6.6 , respectively.

Table XI shows the results of random paired $J_{0}$ measurements under three sets of conditions: at $37^{\circ} \mathrm{C}$, when the perfusate contained no acetate; at $37^{\circ} \mathrm{C}$, when the perfusate contained $10 \mathrm{mM}$ acetate; and at $21^{\circ} \mathrm{C}$, when the perfusate contained $10 \mathrm{mM}$ acetate. The rates of fluid absorption at $37^{\circ} \mathrm{C}$ in the absence of luminal acetate were indistinguishable from zero. Stated in another way, luminal isethionate, sulfate, phosphate, and $3.8 \mathrm{mM} \mathrm{HCO}^{-}$( $\mathrm{pH} 6.6$ ) were unable to support detectable rates of fluid absorption. However, when 10 
$\mathrm{mM}$ acetate was added to perfusing solutions at $37^{\circ} \mathrm{C}$, $J_{v}$ rose to $0.13 \pm 0.04$, which differed from zero at $P$ $<0.002$, and when the system containing $10 \mathrm{mM}$ acetate in the perfusing solution was cooled to $21^{\circ} \mathrm{C}, J_{\text {v }}$ was again indistinguishable from zero, in accord with the fact that $K_{\Delta \mathrm{c}}{ }^{\mathrm{e}}$ was reduced more than twofold on cooling from $37^{\circ}$ to $21^{\circ} \mathrm{C}$ (Table VIII).

\section{DISCUSSION}

The experiments reported in this paper were intended to assess the nature and contributions of anion fluxesspecifically, net lumen to bath $\mathrm{Cl}^{-}$flux, net $\mathrm{HCO}^{-}$absorption, and net disappearance of acetate from luminal solutions-to expected net $\mathrm{Na}^{+}$flux and observed rates of fluid absorption in isolated rabbit superficial proximal straight tubules exposed to symmetrical $\mathrm{HCO}_{3}-\mathrm{KR}$ solutions containing $95 \% \mathrm{O}_{2}-5 \% \mathrm{CO}_{2}$ at $\mathrm{pH}$ 7.4. We emphasize again that the experimental data, and the analysis which follows, are applicable only to these $\mathrm{Cl}^{-}$permselective superficial proximal straight tubules, and not necessarily to juxtamedullary proximal straight tubules, since the latter are $\mathrm{Na}^{+}$rather than $\mathrm{Cl}^{-}$permselective (11).

To analyze the present results, we made three general assumptions. First, as in previous studies $(1,9)$, we consider that temperature-sensitive events, e.g., fluid absorption from tubules perfused with symmetrical $\mathrm{HCO}_{\mathrm{s}}-\mathrm{KR}$ solutions (1, 9; Tables $\mathrm{V}$ and VIII) or the greater values of $K_{\mathbf{A c}}{ }^{\bullet}$ with respect to $K_{\mathbf{A c}}{ }^{1}$ (Tables VII and VIII), depend on conservative processes, such as net active ion transport from lumen to bath and/or cellular consumption of a particular ionic species. The assumption appears warranted since, for these conditions, both $J_{\mathrm{V}}$ and $V_{\mathrm{e}}$ become zero either by cooling from $37^{\circ}$ to $21^{\circ} \mathrm{C}(1,9$; Tables $\mathrm{V}$ and VIII) or by exposure to ouabain at $37^{\circ} \mathrm{C}(1,9)$; at $21^{\circ} \mathrm{C}, K_{\Delta c}{ }^{\circ}$ falls to values nearly the same as those for $K_{\mathrm{Ac}}{ }^{1}$ at $37^{\circ} \mathrm{C}$ (Tables VII and VIII); and at $21^{\circ} \mathrm{C}$, there is no rise in tubular fluid $\mathrm{Cl}^{-}$concentration. Second, we consider that the primary effect of acetazolamide or ethoxzolamide in these tubules is to inhibit carbonic anhydrase-catalyzed $\mathrm{CO}_{2}$ hydration $(15,16)$, since these agents reduce fluid absorption in tubules exposed to symmetrical $\mathrm{HCO}_{3}-\mathrm{KR}$ solutions containing $95 \% \mathrm{O}_{2}-5 \% \mathrm{CO}_{2}$ but have no effect on fluid transport in tubules exposed to symmetrical $\mathrm{Cl}-\mathrm{KR} / \mathrm{O}$, solutions containing neither $\mathrm{HCO}_{3}^{-}$nor $\mathrm{CO}_{2}$ (Tables III and IV). Third, based on the facts that (a) $\mathrm{NaCl}$ dilution potentials in these tubules appear to be expressed across symmetrical extracellular interfaces containing neutral polar sites ( 1 ), and $(b)$ these tubules have remarkably low transepithelial electrical resistances (i.e., approximately $5 \mathrm{ohm} \cdot \mathrm{cm}^{2}[3]$ ), we assume, as discussed in detail previously $(1,9)$, that passive ion permeation in these tubules, as in other electrically leaky epithelia $(35,36)$, involves a paracellular route.
In this frame of reference, five general conclusions emerge from the present studies. First, net $\mathrm{Cl}^{-}$absorption accounted for approximately $27.5 \%$ of the expected net $\mathrm{Na}^{+}$flux during fluid absorption from tubules exposed to symmetrical $\mathrm{HCO}_{3}-\mathrm{KR}$ solutions containing $95 \% \mathrm{O}_{2}-5 \% \mathrm{CO}_{2}$ (Table II) ; the rise in tubular fluid $\mathrm{Cl}^{-}$concentrations during fluid absorption depended on net conservative luminal efflux of other anions, since tubular fluid $\mathrm{Cl}^{-}$concentrations remained constant when fluid absorption was reduced to zero by cooling to $21^{\circ} \mathrm{C}$. Second, $\mathrm{CO}_{2}$ and carbonic anhydrase-sensitive net $\mathrm{HCO}_{3}{ }^{-}$absorption accounted for $40-60 \%$ of the expected net $\mathrm{Na}^{+}$flux in tubules exposed to symmetrical $\mathrm{HCO}_{3}-$ $\mathrm{KR}$ solutions containing $95 \% \quad \mathrm{O}_{2}-5 \% \quad \mathrm{CO}_{2}$ (Tables III, IV, VIII), and was responsible, at least in part, for the rise in tubular fluid $\mathrm{Cl}^{-}$concentrations. Third, it seems probable that an acetazolamide-insensitive component of $\mathrm{HCO}_{s}^{-}$absorption occurred, since $\mathrm{Cl}^{-}$accounted for slightly less than two-thirds of the expected net $\mathrm{Na}^{+}$ flux under conditions where $\mathrm{HCO}_{8}^{-}$was the only other probable counterion for both expected net $\mathrm{Na}^{+}$flux and observed net fluid absorption rates significantly different from zero (Tables VI, XI). Fourth, the difference between $K_{\mathrm{Ac}}{ }^{\circ}$ and $K_{\mathrm{Ac}}{ }^{1}$ depended on conservative processes unaffected by carbonic anhydrase inhibitors (Tables VII and VIII) or $\mathrm{CO}_{2}$ exclusion from perfusing media (cf. Results). Under appropriate conditions, net disappearance of luminal acetate accounted for approximately one fourth of the expected net $\mathrm{Na}^{+}$flux during net fluid absorption (Table X). Finally, fluid absorption from tubules exposed to symmetrical $\mathrm{HCO}_{3}-\mathrm{KR}$ solutions containing $95 \% \mathrm{O}_{2}-5 \% \mathrm{CO}_{2}$ was unaffected, within experimenal error, by omitting acetate from bathing media (Table IX). We now consider these processes in further detail.

The mode of $\mathrm{Cl}^{-}$transport. If passive $\mathrm{Cl}^{-}$transport involves an extracellular route $(1,9)$, the contribution of passive $\mathrm{Cl}^{-}$transport to net $\mathrm{Cl}^{-}$absorption requires analysis of two events : $\mathrm{Cl}^{-}$flux across junctional complexes; and $\mathrm{Cl}^{-}$flux from intercellular spaces to bathing media. The observations of Welling and Grantham (37) indicate that the peritubular basement membranes of these tubules are rather permeable to albumin; consequently, we consider, as in an earlier analysis (9), that the $\mathrm{Cl}^{-}$reflection coefficient for these peritubular basement membranes is zero. Given the hydraulic conductivity of these peritubular basement membranes, which exceeds $0.4 \mathrm{~mm} \mathrm{~s}^{-1} \mathrm{~atm}^{-1}$ (37), it may be shown (9) that, for $J_{v}$ values in the range of $0.4 \mathrm{nl} \mathrm{min} \mathrm{mm}^{-1}$ (i.e., those reported in Table II), one requires negligible hydrostatic gradients, i.e., $0.1-0.2 \mathrm{~cm} \mathrm{H}_{2} \mathrm{O}$, between intercellular spaces and bath. Finally, it seems probable that, in these tubules, there is little voltage attenuation (1) or $\mathrm{Cl}^{-}$accumulation (9) in intercellular spaces. 
Thus, to a crude first approximation, one may express the diffusional $\left(J_{\mathbf{c l}^{d}}\right)$ and entrained $\left(J_{\mathrm{Cl}}{ }^{\circ}\right)$ components of $\mathrm{Cl}^{-}$flux in terms of bulk-phase driving forces and $P_{\mathrm{cl}}$, the observed transepithelial $\mathrm{Cl}^{-}$permeability coefficient.

Given these considerations, the diffusional component of $\mathrm{Cl}^{-}$flux may be approximated $(9,38-40)$ by

$$
\begin{aligned}
J_{\mathrm{Cl}^{\mathrm{d}}} \simeq-P_{\mathrm{Cl}}\left([\mathrm{Cl}]^{j}-[\overline{\mathrm{Cl}}]^{\mathrm{l}}\right) \\
+\frac{P_{\mathrm{Cl}} \mathrm{F}}{R T} \bar{V}_{e} \frac{\left([\overline{\mathrm{Cl}}]^{1}+[\mathrm{Cl}]^{b}\right)}{2}
\end{aligned}
$$

where $J_{\mathrm{cl}^{\mathrm{d}}}{ }^{\mathrm{d}}\left(\mathrm{eq} \mathrm{cm}^{-2} \mathrm{~s}^{-1}\right)$ is the net transepithelial diffusional flux, $P_{\mathrm{cr}}$ is the transepithelial $\mathrm{Cl}^{-}$permeation coefficient, $[\overline{\mathrm{Cl}}]^{1}$ is the arithmetic mean of the $\mathrm{Cl}^{-}$concentrations in perfusing and collected solutions, $[\mathrm{Cl}]^{\mathrm{b}}$ is the bathing solution $\mathrm{Cl}^{-}$concentration, and $\bar{V}$ e is the arithmetic mean of the spontaneous transepithelial voltage at the perfusing and collecting ends of the tubules during fluid absorption. Previous studies have shown that for experimental conditions identical to those listed in Table II, $P_{\mathrm{c} 1}$ and $\bar{V}_{\mathrm{e}}$ are $0.73 \mu \mathrm{m} \mathrm{s}^{-1}$ and $-0.16 \mathrm{mV}$, respectively. From Table II, $[\overline{\mathrm{Cl}}]^{1}$ is $122.1 \mathrm{mM}$. From these values together with the experimental conditions for Table II, $J_{\mathrm{cl}^{d}}{ }^{d}$ computed from eq. 4 is $0.453 \mathrm{neq} \mathrm{s}^{-1} \mathrm{~cm}^{-2}$ or 19.0 peq $\mathrm{min}^{-1} \mathrm{~mm}^{-1}$, in comparison to $15.7 \mathrm{peq} \mathrm{min}^{-1}$ $\mathrm{mm}^{-1}$, the observed $J_{\mathrm{Cl}^{1}}{ }^{\text {net }}$ in Table II.

The estimates of $J_{\mathbf{c l}^{\mathrm{d}}}$ according to eq. 4 , in comparison to the observed values of $J_{\mathrm{cl}^{\text {net }}}$ in Table II, imply that entrainment of solute and solvent flows contributed negligibly to net $\mathrm{Cl}^{-}$transport. $\sigma_{\mathrm{cl}}$, the $\mathrm{Cl}^{-}$reflection coefficient in these tubules, is in the range 0.78-0.95, and, for fluid absorption linked solely to passive ion flows, entrainment of $\mathrm{Cl}^{-}$flux to solvent flow makes a relatively small contribution, with respect to $\mathrm{Cl}^{-}$diffusion, to net $\mathrm{Cl}^{-}$transport (9). In the present instance, the entrained component of net $\mathrm{Cl}^{-}$flux may be approximated (1, 9, $38,40)$ as

$$
J_{\mathrm{Cl}^{\circ}} \simeq{ }_{\beta} J_{v}\left(1-\sigma_{\mathrm{Cl}}\right) \frac{\left([\overline{\mathrm{Cl}}]^{1}+[\mathrm{Cl}]^{\mathrm{b}}\right)}{2},
$$

where $\beta$ is the fraction of net fluid absorption traversing junctional complexes (9). The latter is not known for the present experimental conditions, and, as indicated above, only the range of values for $\sigma_{\mathrm{Cl}}$ have been evaluated (9). However, choosing the maximum value of unity for $\beta$ and 0.87 for $\sigma_{\mathrm{Cl}}$ (i.e., the mean of 0.78 and 0.95 , the range of $\sigma_{\mathrm{Cl}}$ values in these tubules; ref. 9), $J_{\mathrm{c} 1}{ }^{\circ}$ computed according to eq. 5 is $0.138 \mathrm{neq} \mathrm{s}^{-1} \mathrm{~cm}^{-2}$ or 5.8 peq $\mathrm{min}^{-1} \mathrm{~mm}^{-1}$, or $30 \%$ of the $J_{\mathrm{cl}^{a}}{ }^{a}$ values computed from eq. 4. In short, these approximations are consistent with the view that net $\mathrm{Cl}^{-}$absorption in tubules perfused and bathed with symmetrical $\mathrm{HCO}_{s}-\mathrm{KR}$ solution (i.e., Table III) was passive, mainly diffusional in nature.

$\mathrm{HCO}^{-}$absorption. Acetazolamide and ethoxzolamide reduced fluid absorption by $40-60 \%$ with no consistent change in transepithelial voltage when the tubules were perfused and bathed with $\mathrm{HCO}_{3}-\mathrm{KR}$ buffers containing 95\% $\mathrm{O}_{2}-5 \% \mathrm{CO}_{2}$ (Tables III and VIII), but had no effect on fluid absorption from $\mathrm{CO}_{2}$ and $\mathrm{HCO}_{3}^{-}$free media (Table IV). We infer from these data that approximately half of the expected $\mathrm{Na}^{+}$flux from tubules exposed to symmetrical $\mathrm{HCO}_{3}-\mathrm{KR}$ solutions containing $95 \% \mathrm{O}_{2}-5 \% \mathrm{CO}_{2}$ was accompanied by $\mathrm{HCO}_{3}^{-}$generated by carbonic anhydrase-catalyzed $\mathrm{CO}_{2}$ hydration; and that $\mathrm{HCO}_{3}^{-}$absorption was responsible for a major component of the rise in tubular fluid $\mathrm{Cl}^{-}$concentrations (Table II). These data shed no light on the molecular events involved in $\mathrm{HCO}_{3}^{-}$absorption from these tubule segments. But they are consistent with a number of partially divergent views (12-20) concerning the mode of $\mathrm{HCO}^{-}$salvage by the proximal nephron, all of which involve, at a minimum, carbonic anhydrase-catalyzed hydration of $\mathrm{CO}_{2}$ by tubular cells.

It is worth noting in this regard that appreciable $\mathrm{HCO}^{-}$absorption by the in vivo proximal nephron continues in the presence of virtually complete inhibition of renal carbonic anydrase activity (12-20). At least two hypotheses have been set forth to account for this phenomenon. One of these, developed by Rector (14), argues that $\mathrm{H}_{2} \mathrm{CO}_{3}$ recycling from tubular fluid in an acid disequilibrium state, to proximal tubular cells in an alkaline disequilibrium state, provides an additional source for cellular protons. A second argument, set forth independently by Maren $(15,20)$ and by Brodsky and Schilb (41), proposes direct transepithelial $\mathrm{HCO}_{3}^{-}$transport which may be independent of cellular carbonic anhydrase activity.

A similar issue arises in connection with the present experiments. Table VI shows that in the presence of $2.25 \mathrm{mM}$ acetazolamide, approximately one third of expected $\mathrm{Na}^{+}$absorption, i.e., 11.3 peq $\mathrm{min}^{-1} \mathrm{~mm}^{-1}$, was not accounted for by the measured net $\mathrm{Cl}^{-}$flux. And the other agents and/or anions in the perfusing solutions used in Table VI, i.e., urea, $\mathrm{SO}_{4}=\mathrm{HPO}^{\circ} / \mathrm{HPO}^{-}$, and isethionate, were not capable of supporting net solute or fluid absorption (Table XI). But the present experimental data provide no information about whether this anion moiety represents $\mathrm{HCO}_{8}{ }^{-}$absorption due to $\mathrm{H}_{2} \mathrm{CO}_{3}$ recycling from lumen to cell (14), a direct $\mathrm{HCO}^{-}$absorption process $(13,20,41)$, or transport of other, unidentified anions by a different process.

Acetate transport. It is evident from Tables VIII and IX that the greater values of $K_{\mathrm{Ac}}{ }^{\circ}$ with respect to $K_{\mathrm{Ac}}{ }^{1}$ depend on carbonic anhydrase-insensitive, temperaturedependent events. At least two classes of explanations, 
individually or in unison, might have accounted for the disparity between $K_{\mathbf{A c}}{ }^{\circ}$ and $K_{\mathbf{A c}}{ }^{1}$. There may have been net lumen-to-bath transport, presumably active, of the acetate species. Alternatively, luminal acetate might have been consumed by tubular cells. Acetate is a renal metabolic substrate $(42,43)$, and it has been suggested that acetate, lactate, and pyruvate may be converted to acylglycines within renal tubular cells (44). Moreover, proximal tubular lactate absorption may depend on diffusion of lactate across luminal surfaces driven by lumen to cell lactate concentration gradients produced by cellular consumption of lactate (32). Consequently, it may be that in the present experiments (Table VII) $K_{\mathbf{A c}}{ }^{\circ}$ exceeded $K_{\Delta c}{ }^{\prime}$ because of preferential metabolic consumption of luminal rather than contraluminal acetate.

In either instance, i.e., net lumen-to-bath acetate flux or cellular consumption of luminal acetate, it is clear that net luminal acetate efflux may contribute, under appropriate conditions, to fluid absorption. Thus, in the experiments listed in Tables IX and X, where net luminal $\left[{ }^{14} \mathrm{C}\right]$ acetate disappearance could be evaluated, the latter accounted for approximately one fourth of fluid absorption and expected net $\mathrm{Na}^{+}$flux. Likewise, in $\mathrm{Ta}-$ ble XI, the addition of acetate to luminal solutions increased temperature-sensitive fluid absorption from values indistinguishable from zero to $0.13 \mathrm{nl} \mathrm{min} \mathrm{mm}^{-1} \mathrm{~mm}^{-1}$.

In the case of the acetate influx measurements ( $\mathrm{Ta}$ ble VII), certain factors are noteworthy. The bath to lumen influx coefficients of inorganic ions such as $\mathrm{Na}^{+}$ and $\mathrm{Cl}^{-}$are considered to be the passive ionic permeability coefficients for these ions in isolated proximal tubules $(1,9,11,22)$. But the $K_{\mathbf{A c}}{ }^{1}$ values in Table VII might have depended not only on passive permeation of acetate via the paracellular route traversed by $\mathrm{Na}^{+}$and $\mathrm{Cl}^{-}$in these tubules $(1,9)$, but also on either transcellular acetate transport via an organic acid secretory system $(29,30)$, or, since the ${ }^{14} \mathrm{C}$ collected in luminal fluids during $K_{\mathbf{A c}}{ }^{1}$ measurements (Table VIII) was not identified uniquely as $\left[{ }^{14} \mathrm{C}\right]$ acetate, or as cellular secretion of a ${ }^{14} \mathrm{C}$-labeled metabolic product of acetate. When considered in this context, the values of $K_{\mathrm{Ac}}{ }^{1}$ in Table VII represent an upper limit for $P_{\Delta c}$, the passive permeability coefficient for acetate in these tubules.

However, two considerations suggest that the values of $K_{\mathrm{Ac}}{ }^{\prime}$ may have depended primarily on a passive transport process. As shown in Table IX, exclusion of acetate from bathing media did not significantly reduce fluid absorption. Stated alternatively, metabolic consumption and/or transport of contraluminal acetate, for the conditions in Table VIII, had a negligible effect on ion and fluid transport in these tubules. Second, the values of $K_{\Delta c^{\circ}}$ at $21^{\circ} \mathrm{C}$ and zero net fluid absorption, $0.18 \pm 0.02 \mu \mathrm{m} / \mathrm{s}$ (Table VIII), were in close accord with those for $K_{\mathrm{Ac}}{ }^{1}$ during fluid absorption at $37^{\circ} \mathrm{C}, 0.14 \pm 0.02$ $\mu \mathrm{m} / \mathrm{s}$ (Table VII). To the extent that these data indicate the absence of significant transcellular transport and/or metabolic usage of bathing fluid acetate, we may conclude tentatively that the passive permeability coefficient $\left(P_{\Delta c}\right)$ for acetate in these tubules was in the range of $0.14-0.18 \mu \mathrm{m} / \mathrm{s}$ (Tables VII and VIII).

Uncertainties concerning $\mathrm{NaCl}$ absorption. Based on the results in Tables III-V, VIII, it seems reasonable to assume that approximately $40-60 \%$ of $\mathrm{Na}^{+}$absorption from tubules exposed to symmetrical $\mathrm{HCO}_{\mathrm{s}} \mathrm{KR}$ solutions was accompanied by $\mathrm{HCO}_{3}^{-}$. Likewise, if the results in Table $\mathrm{X}$ provide an index to net luminal acetate efflux, one might deduce that an appreciable fraction, but less than that in Table $\mathrm{X}$, of $\mathrm{Na}^{+}$absorption was accompanied by acetate when the latter was present in bathing media (e.g., Table II). Such a stoichiometric relationship between $\mathrm{Na}^{+}, \mathrm{HCO}_{3}^{-}$, and acetate seems at least plausible, since the results in Table II indicate directly that net $\mathrm{NaCl}$ absorption accounted for approximately one-fourth of the expected net $\mathrm{Na}^{+}$flux. In this connection, major questions arise concerning a detailed rather than approximating analysis of $\mathrm{Cl}^{-}$flows in these tubules, and the mode of $\mathrm{NaCl}$ transport.

With regard to $\mathrm{Cl}^{-}$transport, the sum of $J_{\mathrm{Cl}^{d}}{ }^{\mathrm{d}}$ and $J_{\mathrm{Cl}}{ }^{\circ}$ with eq. 4 and 5 respectively, yields a value of 24.8 peq $\min ^{-1} \mathrm{~mm}^{-1}$ for the approximate net passive $\mathrm{Cl}^{-}$flux, substantially greater than the observed rate of 15.7 peq $\mathrm{min}^{-1} \mathrm{~mm}^{-1}$ (Table II) for net $\mathrm{Cl}^{-}$absorption. These enabling calculations clearly require more rigorous evaluation. In regard to the mode of transport for the fraction of $\mathrm{Na}^{+}$absorption accompanying $\mathrm{Cl}^{-}$(Table II), at least two possibilities might be considered. First, the spontaneous transepithelial voltage in tubules exposed to symmetrical $\mathrm{HCO}_{s}-\mathrm{KR}$ solutions is -1.0 to $-1.5 \mathrm{mV}$ lumen negative at the start of perfusion (1, $3,9)$, i.e., before the rise in tubular fluid concentration (Table II). Consequently it might be argued (1) that active, rheogenic $\mathrm{Na}^{+}$transport occurs in regions where the transepithelial voltage is lumen negative. Second, it seems probable that the transepithelial voltage becomes lumen positive coincident with the rise in tubular fluid $\mathrm{Cl}^{-}$concentrations in these superficial proximal straight tubules $(1,9)$ and in isolated (4-6) and in vivo (10) superficial proximal convolutions (although not in juxtamedullary proximal straight tubules; ref. 11); and prior observations have provided direct experimental evidence for passive $\mathrm{Na}^{+}$absorption driven by lumen-positive transepithelial voltages in isolated proximal straight tubules (9). It is evident from these considerations that in the case of fluid absorption from symmetrical $\mathrm{HCO}_{2}-$ $\mathrm{KR}$ solutions, a rigorous quantitative analysis of $\mathrm{Cl}^{-}$ absorption and an assessment of the magnitudes of the passive and active moieties of $\mathrm{Na}^{+}$flux accompanying $\mathrm{Cl}^{-}$will require, at a minimum, solution of the flow- 
diffusion equations for solute and solvent flows in intercellular spaces for tubules under the conditions listed in Table II.

\section{ACKNOWLEDGMENTS}

We are grateful to our research assistant B. E. Richey for able assistance in carrying out these experiments.

This work was supported by research grants from the American Heart Association (75-805), the National Science Foundation (BMS 74-13645), and the National Institutes of Health (5-R01-AM14873).

\section{REFERENCES}

1. Schafer, J. A., S. L. Troutman, and T. E. Andreoli. 1974. Volume reabsorption, transepithelial potential differences, and ionic permeability properties in mammalian superficial proximal straight tubules. J. Gen. Physiol. 64: 582-607.

2. Kokko, J. P., M. B. Burg, and J. Orloff. 1971. Characteristics of $\mathrm{NaCl}$ and water transport in the renal proximal tubule. J. Clin. Invest. 50: 69-76.

3. Lutz, M. D., J. Cardinal, and M. B. Burg. 1973. Electrical resistance of renal proximal tubule perfused in vitro. Am. J. Physiol. 225: 729-734.

4. Kokko, J. P. 1973. Proximal tubule potential difference. Dependence on glucose, $\mathrm{HCO}_{3}$ and amino acids. J. Clin. Invest. 52 : 1362-1367.

5. Lutz, M., J. Cardinal, M. Burg, and J. Orloff. 1973. Electrical potential difference (p.d.) and fluid absorption by proximal convoluted tubules. Abstracts of the Sixth Annual Meeting of the American Society of Nephrology (Wash., D. C.). 69.

6. Cardinal, J., M. D. Lutz, M. B. Burg, and J. Orloff. 1975. Lack of relationship of potential difference to fluid absorption in the proximal renal tubule. Kidney Int. 7: 94-102.

7. Clapp, J. R., J. F. Watson, and R. W. Berliner. 1963. Osmolality, bicarbonate concentration, and water reabsorption in proximal tubule of the dog nephron. $\mathrm{Am}$. J. Physiol. 205: 273-280.

8. Gottschalk, C. W., W. E. Lassiter, and M. Mylle. 1960. Localization of urine acidification in the mammalian kidney. Am. J. Physiol. 198 : 581-585.

9. Schafer, J. A., C. S. Patlak, and T. E. Andreoli. 1975. A component of fluid absorption linked to passive ion flows in the superficial pars recta. J. Gen. Physiol. 66: 445-471.

10. Barratt, L. J., F. C. Rector, Jr., J. P. Kokko, and D. W. Seldin. 1974. Factors governing the transepithelial potential difference across the proximal tubule of the rat kidney. J. Clin. Invest. 53: 454-464.

11. Kawamura, S., M. Imai, D. W. Seldin, and J. P. Kokko. 1975. Characteristics of salt and water transport in superficial and juxtamedullary straight segments of proximal tubules. J. Clin. Invest. 55: 1269-1277.

12. Rector, F. C., Jr., D. W. Seldin, A. D. Roberts, Jr., and J. S. Smith. 1960. The role of plasma $\mathrm{CO}_{2}$ tension and carbonic anhydrase activity in the renal reabsorption of bicarbonate. J. Clin. Invest. 39: 1706-1721.

13. Rector, F. C., Jr., N. W. Carter, and D. W. Seldin. 1965. The mechanism of bicarbonate reabsorption in the proximal and distal tubules of the kidney. J. Clin. In vest. $44:$ 278-290.

14. Rector, F. C., Jr. 1973. Acidification of the urine. Handb. Physiol. Sec. 8. 431-454.
15. Maren, T. H. 1967. Carbonic anhydrase: chemistry, physiology and inhibition. Physiol. Rev. 47: 595-781.

16. Maren, T. H. 1969. Renal carbonic anhydrase and the pharmacology of sulfonamide inhibitors. In Handbook of Experimental Pharmacology. Diuretica. H. Herkin, editor. Springer-Verlag K.G., Berlin. 24: 195-256.

17. Malnic, G., and M. Mello Aires. 1970. Micropuncture study of anion transfer in proximal tubules of rat kidney. Am. J. Physiol. 218: 27-32.

18. Malnic, G., and G. Giebisch. 1972. Mechanism of renal hydrogen secretion. Kidney Int. 1: 280-296.

19. Kunau, R. T., Jr. 1972. The influence of the carbonic anhydrase inhibitor, Benzolamide (CL-11,366), on the reabsorption of chloride, sodium, and bicarbonate in the proximal tubule of the rat. J. Clin. Invest. 51: 294-306.

20. Maren, T. H. 1974. The relation between renal acidification and bicarbonate reabsorption. A view of $\mathrm{CO}_{2}-$ mediated secretion in renal and other epithelia. In Drugs and Transport Processes. B. A. Callingham, editor. University Park Press, Baltimore, Md. 73-97.

21. Burg, M., J. Grantham, M. Abramow, and J. Orloff. 1966. Preparaiton and study of fragments of single rabbit nephrons. Am. J. Physiol. 210: 1293-1298.

22. Imai, M., and J. P. Kokko. 1972. Effect of peritubular protein concentration on reabsorption of sodium and water in isolated perfused proximal tubules. J. Clin. Invest. 51 : 314-325.

23. Grantham, J. J., P. B. Qualizza, and L. W. Welling. 1972. Influence of serum proteins on net fluid reabsorption of isolated proximal tubules. Kidney Int. 2: 66-75.

24. Ramsey, J. A., R. H. J. Brown, and P. C. Croghan 1955. Electrometric titration of chloride in small volumes. J. Exp. Biol. 32 : 822-829.

25. Grantham, J. 1973. Sodium transport in isolated renal tubules. In Modern Diuretic Therapy in the Treatment of Cardiovascular and Renal Disease. A. F. Lant and G. H. Wilson, editors. Excerpta Medica, Amsterdam. 220-228.

26. Burg, M., and N. Green. 1973. Effect of mersalyl on the thick ascending limb of Henle's loop. Kidney Int. 4: 245-251.

27. Burg, M., L. Stoner, J. Cardinal, and N. Green. 1973. Furosemide effect on isolated perfused tubules. $\mathrm{Am}$. J. Physiol. 225 : 119-124.

28. Burg, M., and N. Green. 1973. Effect of ethacrynic acid on the thick ascending limb of Henle's loop. Kidney Int. 4: 301-308.

29. Grantham, J. J., R. L. Irwin, P. B. Qualizza, D. R. Tucker, and F. C. Whittier. 1973. Fluid secretion in isolated proximal straight renal tubules. Effect of human uremic serum. J. Clin. Invest. 52: 2441-2450.

30. Grantham, J. J., P. B. Qualizza, and R. L. Irwin. 1974. Net fluid secretion in proximal straight renal tubules in vitro. Role of PAH. Am. J. Physiol. 226: 191-197.

31. Tune, B. M., and M. B. Burg. 1971. Glucose transport by proximal renal tubules. Am. J. Physiol. 221: 580585.

32. Höhmann, B., P. F. Fronhert, R. Kinne, and K. Baumann. 1974. Proximal tubular lactate transport in rat kidney: A micropuncture study. Kidney Int. 5: 261270.

33. Schafer, J. A., and T. E. Andreoli. 1972. Cellular constraints to diffusion. The effect of antidiuretic hormone on water flows in isolated mammalian collecting tubules. J. Clin. Invest. 51 : 1264-1278.

34. Schafer, J. A., C. S. Patlak, and T. E. Andreoli. 1974. Osmosis in cortical collecting tubules. A theoretical and 
experimental analysis of the osmotic transient phenomenon. J. Gen. Physiol. 64 : 201-227.

35. Frömter, E., and J. Diamond. 1972. Route of passive ion permeation in epithelia. Nat. New Biol. 235: 9-13.

36. Frizzell, R. A., and S. G. Schultz. 1972. Ionic conductances of extracellular shunt pathway in rabbit ileum. Influence of shunt on transmural sodium transport and electrical potential differences. J. Gen. Physiol. 59: 318346.

37. Welling, L. W., and J. J. Grantham. 1972. Physical properties of isolated perfused renal tubules and tubular basement membranes. J. Clin. Invest. 51 : 1063-1075.

38. Kedem, O., and A. Katchalsky. 1961. A physical interpretation of the phenomenological coefficients of membrane permeability. J. Gen. Physiol. 45: 143-179.

39. Kedem, O., and A. Leaf. 1965. The relation between salt and ionic transport coefficients. J. Gen. Physiol. 49 : 655-662.
40. Ullrich, K. J. 1973. Permeability characteristics of the mammalian nephron. Handb. Physiol. Sec. 8. 12: 377414.

41. Brodsky, W. A., and T. P. Schilb. 1974. The means of distinguishing between hydrogen secretion and bicarbonate reabsorption: Theory and applications to the reptilian bladder and mammalian kideny. Curr. Top. Membranes Transp. 5 : 161-224.

42. Mudge, G. H. 1951. Studies on potassium accumulation by rabbit kidney slices: Effect of metabolic activity. Am. J. Physiol. 165: 113-127.

43. Cohen, J. J., and M. Barac-Nieto. 1973. Renal metabolism of substrates in relation to renal function. Handb. Physiol. Sec. 8. 909-1001.

44. Schachter, D., J. G. Manis, and J. V. Taggart. 1955. Renal synthesis, degradation and active transport of aliphatic acyl amino acids. Relationship to $p$-aminohippurate transport. Am. J. Physiol. 182: 537-544. 